\title{
A abordagem do turismo na criação de unidades de conservação no Polo Costa das Dunas (RN)
}

\section{Tourism approach of the establishment of Protected Natural Areas in Polo Costa das Dunas (RN, Brazil)}

\author{
Fernanda Raphaela Alves Dantas, Kerlei Eniele Sonaglio
}

\begin{abstract}
RESUMO: Compreender o contexto do turismo nas unidades de conservação a partir seus efeitos e do planejamento é necessário para mitigar respostas indesejáveis, sobretudo quando a criação destas áreas é motivada pelo discurso da conservação ambiental aliada ao turismo como solução aos desafios para a sustentabilidade local. Neste entendimento, em abordagem qualitativa, buscou-se analisar qual o propósito e contexto do turismo nas unidades de conservação estaduais em processo de criação no Polo Turístico Costa das Dunas, Rio Grande do Norte (RN), especificamente em dois Parques Estaduais, Parques Estaduais Mangues do Potengi - PEMAP (Natal) e Jiqui - PEJ (Parnamirim). A primeira etapa da pesquisa foi do tipo descritiva, onde realizou-se a análise documental dos processos e atas que tratam da criação dos Parques, bem como, de atas de reuniões do citado Polo. Na segunda etapa empreendeu-se entrevista semiestruturada com o Núcleo de Unidades de Conservação do IDEMA sobre aspectos relacionados ao planejamento do turismo pretendido para as áreas. Constatou-se que os processos de criação dos parques estão estagnados, sendo o PEMAP na dependência de continuidade em estudos técnicos e socioeconômicos e, o PEJ, aguardando a cessão de área incluída nas delimitações da UC. Sobre os atores do turismo do setor público ou privado e das comunidades do entorno, notou-se que o envolvimento é tímido e reticente, o que pode resultar em conflitos socioeconômicos posteriores a criação das UC. Em relação aos debates ocorridos nas reuniões do Polo, percebeu-se a escassez e incipiência do tema em pauta, o que demonstra um distanciamento na perspectiva do planejamento do turismo quanto as novas áreas de potencial atratividade. Dessa forma, acredita-se que discussões e participação dos diferentes atores interessados na criação desses Parques necessitam de mais amplitude e aprofundamento, visando o alcance de um planejamento integrativo mais assertivo e seguro.
\end{abstract}

PALAVRAS-CHAVE: Turismo; Planejamento Turístico; Unidades de Conservação; Polo Costa das Dunas (RN). 
ABSTRACT: It is necessary to understand the context of Tourism in Protected Natural Areas, taking into account its effects and planning, in order to mitigate undesirable results, especially when the establishment of these areas is driven by a discourse of environmental conservation combined with Tourism as the answer for the local sustainability challenges. Based on this understanding and through a qualitative approach, we sought to analyze the purpose and context of tourism in Protected Natural Areas of the Rio Grande do Norte (RN) State that are being established in the touristic Polo Costa das Dunas, specifically in two State parks, Mangues do Potengi - PEMAP (Natal) and Jiqui - PEJ (Parnamirim). The first stage of the research was of a descriptive type, with the analysis of processes and minutes documents related to the establishment of the parks, as well as of meeting minutes of the mentioned Polo. In the second stage, a semi-structured interview took place in the Center of Conservation Units of IDEMA on aspects related to the intended tourism planning for the areas. It was found that the processes of establishing the parks are stagnant; PEMAP depends on the continuity of technical and socioeconomic studies and PEJ awaits for the assignment of the area defined by the area. Regarding tourism actors in the public or private sector and surrounding communities, it was noted that their involvement is timid and reticent, which can result in socioeconomic conflicts following the establishment of the area. In relation to debates that took place at the Polo meetings, the scarcity and incipience of the topic at hand was noticed, demonstrating a gap in the perspective of tourism planning in relation to the new areas of potential attractiveness. Thus, it is believed that the discussions and participation of different actors interested in the establishment of these parks need to be more extent and with further development, aiming at achieving a more assertive and secure integrative planning.

KEYWORDS: Tourism; Tourism Planning; Protected Natural Areas; Polo Costa das Dunas (RN, Brazil).

\section{Introdução}

A instituição de Unidades de Conservação (UC) no Brasil surge em um cenário de necessidade de proteção e conservação de elementos da biodiversidade, tendo em vista que, a ação antrópica possibilita resultados de efeitos negativos e irreversíveis para esses espaços, nota-se preocupação de movimentos com discussões e debates que fortaleceram avanços na temática.

Dessa forma, o Sistema Nacional de Unidades de Conservação da Natureza (SNUC) foi criado em 2000, de acordo com Suarez (2010) a instituição desse sistema foi uma das mais importantes medidas na atualidade com propósito de proteção aos recursos naturais e a vida nos diferentes ecossistemas do Brasil, além de contribuir para a não destruição ambiental dessas áreas protegidas pelo SNUC. 
O SNUC delimita dois grupos de UC, e 12 categorias, entre essas, está a categoria de Parque Nacional (PARNA), dentro do Grupo de Proteção Integral, traz em seus objetivos a preservação dos ecossistemas naturais de relevância ecológica e beleza cênica; possibilita a realização de pesquisas científicas, atividades de educação e interpretação ambiental, de recreação e o turismo ecológico (SNUC, 2000).

No Brasil, os números quanto às áreas naturais protegidas são expressivos. Em agosto de 2020 eram 777 unidades de proteção integral com uma área de 663. 474,05 km² e 1.669 unidades de uso sustentável, com área de 1.888.722,67 $\mathrm{km}^{2}$, o que totaliza 2.446 unidades de conservação em área de 2.552.196,72 km² (CNUC/MMA, 2020).

Tratando sobre as atividades de caráter socioeconômicas propostas para as UC, o uso turístico é parte integrante. No mundo, os turistas estão cada vez mais buscando a visitação em parques e reservas na tentativa de vivenciar experiências que os aproximem, e colabore na compreensão e valorização do meio ambiente natural, no sentindo de encontrar nesses espaços aquilo que o próprio cotidiano das metrópoles não oferece mais (LIMA, 2003).

Em 2019, de acordo com o Instituto Chico Mendes da Biodiversidade ICMBlo, a visitação em UC federais brasileiras ultrapassou o número de 15 milhões, o que representa um aumento de $20,4 \%$ em relação ao ano de 2018. Destaca-se ainda que a categoria de Parque Nacional é a que mais recebe visitantes com o correspondente a $64 \%$ do total. Em seguida, apresenta-se as Áreas de Proteção Ambiental (APA) sendo a segunda categoria que mais recebeu visitas no ano de 2019 correspondendo a $21 \%$ do total (ICMBIO, 2020).

No entanto, a visitação realizada sem limites, planejamento e sem práticas que corroborem com a conservação do espaço, pode resultar em impactos negativos em múltiplas dimensões sociais, econômicas, culturais e ambientais. Nesse sentido, o planejamento turístico deve ser entendido como uma ferramenta indispensável para a gestão e organização das UC que permitem o uso público e turístico, ressaltando a necessidade de participação e envolvimento de atores do turismo no processo de planejamento que antecede a criação dessas áreas.

No RN, o órgão responsável pela gestão e criação de UC é o Instituto de Desenvolvimento Sustentável e Meio Ambiente - IDEMA/RN, por meio do Núcleo de Unidades de Conservação - NUC, com a missão de planejar, definir, propor a criação, implantar e gerir as UC de forma participativa, além disso, tem finalidade de cumprir o que é estabelecido no SNUC.

O RN, de acordo com o IDEMA (2014), possui 10 UC legalmente instituídas, correspondendo a 238 mil hectares, além disso, o IDEMA (2014) está investindo na criação de novas Unidades Estaduais que representarão um incremento superior a 120 mil hectares, entre as UC em criação estão o Parque Estadual dos Mangues do Potengi, em Natal; Parque Estadual do Jiqui, localizado em Parnamirim. 
O Parque Estadual dos Mangues do Potengi (PEMAP) e o Parque Estadual do Jiqui (PEJ) estão localizados no Polo Turístico Costa das Dunas (PCD), região litorânea potiguar que possui seus principais atrativos turísticos pautados nos recursos naturais e por vezes, inseridos em áreas protegidas. Dessa forma, reforça-se a necessidade de discussão sobre a criação de novos parques na região turística de maneira que seja possível compreender quais ações e debates a instância regional do turismo realiza quanto a criação de novas unidades.

Diante disso, justifica-se o recorte para o presente estudo o PEMAP e o PEJ por ambos pertencerem a categoria de Parque Nacional pertencentes ao grupo de Proteção Integral, mas ao mesmo tempo, possuir na legislação específica das UC a permissão de uso público e o incentivo a atividade turística.

O PEJ está localizado no município de Parnamirim/RN, compreende uma área de 395 hectares, possuindo área rica em biomas e ecossistemas. O PEMAP está localizado em Natal/RN com abrangência de 824,43 hectares, também com relevantes aspectos ambientais principalmente com enfoque nas florestas manguezais (FUNDEP, 2009).

No Plano de Ação Emergencial dos dois Parques em criação é possível notar o interesse de obter condições de manejo com parâmetros estratégicos que possibilitem a realização de pesquisas científicas, atividades de educação ambiental e o turismo ecológico com subsídios suficientes para atender as necessidades dos visitantes (FUNDEP, 2009).

Sendo assim, o presente artigo tem objetivo compreender como o turismo é abordado no processo de criação de dois parques localizados dentro de uma instância de governança regional do turismo que possui os recursos naturais e suas UC como primordiais no contexto de atratividade turística.

Torna-se relevante pesquisar essa concepção de turismo anteriormente a criação das UC principalmente considerando as que em sua proposta incentiva a visitação turística, pois, percebe-se que após a institucionalização existem impactos indesejáveis que poderiam ter sido minimizados se planejados de uma maneira mais participativa. Nota-se nos trabalhos de Oliveira (2017) e Soares (2011) que em algumas UC instituídas na Região Turística Costa das Dunas existem conflitos associados a não participação de comunidades locais no processo de criação e gestão desses espaços.

Cita-se ainda, que o presente artigo traz contribuição acadêmica, pois observa-se que apesar de elevada produção que aborda a questão do turismo no contexto de áreas naturais protegidas (ANP) ainda são escassas pesquisas voltadas para essa abordagem em UC que se encontram em processo de criação, sendo então, relevante essas investigações antecedentes a instituição das ANP na perspectiva de um planejamento mais assertivo. 


\section{Unidades de Conservação: categorias, processo de criação e o turismo}

A criação de áreas naturais protegidas acontece a partir da necessidade de reservar e ordenar a utilização de recursos naturais, tendo em vista que o uso e exploração inadequados podem resultar em prejuízos irreparáveis para o meio ambiente e para as comunidades que se encontram nos entornos.

De forma acelerada, os números de ANP, que no Brasil, por volta da década de 1970 passaram a ser definidas como Unidades de Conservação, vieram crescendo nas últimas décadas no País nos níveis Federal, Estadual e Municipal, sendo considerado um crescimento fundamental e urgente para garantir a biodiversidade (DRUMMOND et al., 2010).

Dessa forma, entende-se que eventos e conferências com discussões voltadas para as questões ambientais, bem como, o crescimento e pluralidade de categorias de UC contribuíram para o progresso de legislações e criação de instrumentos de gestão e planejamento nesses espaços no Brasil, e que em 2000, um marco relevante para esse contexto, foi a instituição do SNUC.

Sobre o SNUC, BRASIL (2011) diz que esse deve ser entendido como uma maneira especial de ordenamento territorial, com propósito de despertar interesse na sociedade pelo patrimônio natural e cultural protegido pelo SNUC, com perspectiva de aproximação das UC com as pessoas, e, além disso, o Sistema não deve ser visto como um entrave para o desenvolvimento social e econômico.

Entende-se que as UC são espaços que possuem relevância ambiental e existem para atender a necessidade de conservação dos aspectos da biodiversidade, bem como, a geodiversidade, no entanto, é permitido o uso público de forma sustentável. Outro aspecto destacado nessas localidades é o desenvolvimento socioeconômico para as comunidades nos entornos, o que mostra que o SNUC não tem a pretensão de dificultar o desenvolvimento das dimensões socioeconômicas (BRASIL, 2011; SNUC, 2000).

No Quadro 1 (próxima página), serão apresentados de forma sintetizada as categorias que se dividem em dois grupos: I Unidades de Proteção Integral e II Unidades de Uso Sustentável.

É possível notar que as 12 categorias divididas nos dois grupos, estabelecidos pelo SNUC (2000), abarcam objetivos de conservação e uso distintos, que não se apresentam como intocáveis, uma vez que na maioria das UC a visitação é permitida.

Normalmente, uma UC é criada quando existe demanda social na perspectiva de proteger áreas com relevância biológica, cultural, de beleza cênica, ou para o uso sustentável dos recursos naturais por parte das populações tradicionais, sem esquecer que essa criação deve considerar a realidade ambiental do local (LEITE et al., 2011). 
Quadro 1: Categorização das Unidades de Conservação.

Frame 1: Categorización de Unidades de Conservación.

\begin{tabular}{|c|c|}
\hline \multirow{5}{*}{ 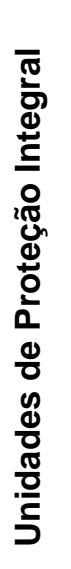 } & $\begin{array}{l}\text { Estação Ecológica (ESEC): Objetivo a preservação da natureza e a realização de } \\
\text { pesquisas científicas; é proibida a visitação pública, exceto quando o objetivo é } \\
\text { educacional. }\end{array}$ \\
\hline & $\begin{array}{l}\text { Reserva Biológica (REBIO): Objetivo a preservação integral da biota e demais atributos } \\
\text { naturais; é proibida a visitação pública, exceto quando o objetivo é educacional. }\end{array}$ \\
\hline & $\begin{array}{l}\text { Parque Nacional (PARNA): Objetivo de preservação dos ecossistemas naturais de grande } \\
\text { relevância ecológica e beleza cênica; possibilita a realização de pesquisas científicas, } \\
\text { atividades de educação e interpretação ambiental, de recreação e o turismo ecológico. }\end{array}$ \\
\hline & $\begin{array}{l}\text { Monumento Natural (MN): Objetivo básico é preservar sítios naturais raros, singulares ou } \\
\text { de grande beleza cênica. Permite visitação pública sujeita ás condições e restrições } \\
\text { estabelecidas no Plano de Manejo da unidade. }\end{array}$ \\
\hline & $\begin{array}{l}\text { Refúgio de Vida Silvestre (RVS): Objetivo é de proteger ambientes naturais onde se } \\
\text { asseguram condições para a existência ou reprodução de espécies ou comunidades da } \\
\text { flora e da fauna. Permite visitação pública sujeita ás condições e restrições estabelecidas. }\end{array}$ \\
\hline \multirow{7}{*}{ 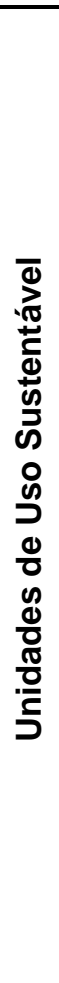 } & $\begin{array}{l}\text { Área de proteção ambiental (APA): Objetivo básico é proteger a diversidade biológica, } \\
\text { disciplinar o processo de ocupação, além de assegurar a sustentabilidade do uso de } \\
\text { recursos naturais. Permite realização de pesquisas científicas, além de visitação pública. }\end{array}$ \\
\hline & $\begin{array}{l}\text { Área de Relevante Interesse Ecológico (ARIE): Objetivo manter os ecossistemas naturais } \\
\text { de importância regional ou local e regular o uso admissível dessas áreas, de modo a } \\
\text { compatibilizá-lo com os objetivos de conservação da natureza. }\end{array}$ \\
\hline & $\begin{array}{l}\text { Floresta Nacional (FLONA): Objetivo básico é o uso múltiplo sustentável dos recursos } \\
\text { florestais e a pesquisa científica, com ênfase em métodos para exploração sustentável de } \\
\text { florestas nativas. Permite visitação pública e incentiva a pesquisa científica. }\end{array}$ \\
\hline & $\begin{array}{l}\text { Reserva Extrativista (RESEX): Objetivos básicos proteger os meios de vida e a cultura } \\
\text { dessas populações, e assegurar o uso sustentável dos recursos naturais da unidade. A } \\
\text { visitação pública é permitida e pesquisas incentivadas. }\end{array}$ \\
\hline & $\begin{array}{l}\text { Reserva Fauna (REFAU): Área natural com populações animais de espécies nativas, } \\
\text { terrestres ou aquáticas, residentes ou migratórias, A visitação pública pode ser permitida, } \\
\text { desde que compatível com o manejo da unidade. }\end{array}$ \\
\hline & $\begin{array}{l}\text { Reserva de Desenvolvimento Sustentável (RDS): Objetivo básico preservar a natureza e } \\
\text { assegurar as condições de reprodução e a melhoria da qualidade de vida e exploração dos } \\
\text { recursos naturais das populações tradicionais, bem como valorizar, conservar e aperfeiçoar } \\
\text { o conhecimento e as técnicas de manejo do ambiente, desenvolvido por estas populações. } \\
\text { Permite e incentiva visitação pública e pesquisas desde que compatível com os interesses } \\
\text { locais e de acordo com os Planos de Manejo. }\end{array}$ \\
\hline & $\begin{array}{l}\text { Reserva Particular do Patrimônio Natural (RPPN): Objetivo é de conservar a diversidade } \\
\text { biológica. Só se permitem visitação se for para pesquisa científica ou visitação com } \\
\text { objetivos turísticos, recreativos e educacionais. }\end{array}$ \\
\hline
\end{tabular}

Fonte: Adaptado do SNUC, 2000.

Source: Adapted of the SNUC, 2000.

O processo de criação das UC também se encontra estabelecido no capítulo IV do SNUC, onde é dito que essas são criadas por ato do Poder Público e deve ser precedida tanto de estudos técnicos como consulta pública, possibilitando a identificação da localização, dimensão e limites mais adequados para a unidade.

Os estudos técnicos devem ser baseados em dados técnicos e científicos, e podem ser realizadas com a colaboração de outros órgãos públicos, universidades, instituições de pesquisa, organizações da sociedade civil, membros da comunidade científica e da população local. Os estudos devem apresentar entre seus aspectos, a caracterização das diferentes formações vegetais e sua fauna associada, caracterização do uso 
do solo, caracterização da população residente e a contextualização da área (ICMBIO, 2008; Brasil, 2008; SNUC, 2000).

No processo de consulta, o Poder Público é obrigado a fornecer informações adequadas à população local e as outras partes interessadas. Apenas na criação de Estação Ecológica ou Reserva Biológica é dispensada a consulta pública. Essa consulta consiste em reuniões públicas, ou a critério do órgão ambiental competente, pode delimitar outras formas de ouvir a população local e de outras partes interessadas. Nesta etapa, devem-se indicar de maneira clara e em linguagem acessível as implicações para as populações, tanto as residentes no interior da unidade proposta quanto às localizadas no entorno (SNUC, 2000; BRASIL, 2008).

Para o ICMBIO (2017) a maior parte demanda por criação de áreas naturais protegidas no Brasil estão relacionadas a manifestação de interesses da sociedade civil, comunidade científica/órgãos públicos, motivados pela necessidade de proteção do patrimônio natural. As etapas constituintes do processo de criação são: análise técnica da proposta, com levantamentos e elaboração de relatórios com foco no meio natural, socioeconômico, cultural e fundiário, esta etapa é concretizada com a elaboração da proposta preliminar com definição de limites e categoria da UC.

Logo adiante, a proposta será apresentada e discutida junto à sociedade na etapa consultiva, realizada por meio de consultas públicas, reunião e análises das informações e solicitações de todo o processo. A proposta de criação da UC federal segue para o Ministério do Meio Ambiente, sendo então realizadas análises técnicas e jurídicas complementares, para assim ser encaminhada ao Chefe do Poder Executivo, acompanhada de toda a documentação do processo. Por fim, a UC é criada por ato de poder executivo após assinatura e publicação no Diário Oficial da União o respectivo decreto.

Torna-se relevante entender que com planejamento e gestão adequada nesses lugares a criação das UC reflete positivamente em diferentes aspectos, além de contribuir com a conservação de áreas naturais que possuem relevância ambiental, pode ser proporcionado também outros fatores que auxiliam para o desenvolvimento do País, tendo em vista que, as UC não são espaços intocáveis.

Nesse contexto, de acordo com Gurgel et al., (2009) e SNUC (2000) o turismo apresenta-se como principal tipo de uso dos Parques e das Reservas Particulares do Patrimônio Natural (RPPN), ressaltando que de acordo com o CNUC/MMA (2020) da área total de unidades no Brasil, as RPPN representam $40,60 \%$ do total, os Parques $19,42 \%$ e Áreas de Proteção Ambiental 15,33\%. Sendo os três, respectivamente, os mais representativos no País.

Sendo assim, entende-se que o turismo se faz presente e relevante para discussão da criação, implantação e gestão das unidades de conservação, tendo em vista que, esse surge como uma das principais fontes de incentivos para visitação dessas áreas, de forma que seja possível 
contribuir com aspectos econômicos, socioambientais e culturais das UC, bem como das comunidades que se encontram nos entornos desses espaços.

\section{Impactos do turismo em UC e abordagem do planejamento turístico}

O turismo é apresentado no contexto das áreas naturais protegidas como um dos incentivos para contribuição com a gestão e desenvolvimento desses espaços, que apesar de possuírem como principal objetivo a conservação de recursos naturais e a biodiversidade, também se constituem em possibilidade de melhor desenvolvimento socioeconômico e valorização da cultura local.

Para Pires (2006) os impactos ambientais do turismo são amplos e multifacetados, no sentido de ser possível considerar e reconhecer que o desenvolvimento do turismo apresenta respostas de efeitos adversos (negativos) ou de efeitos benéficos (positivos) em relação ao meio ambiente natural e por se tratar de uma atividade que pode gerar modificações em amplo sentido.

Segundo Sonaglio (2006) nas áreas naturais protegidas do Brasil, o ecoturismo ocorre de maneira expressiva, tendo em vista as características dessas áreas que constituem o principal atrativo para esse tipo de turismo. Para a autora, essa atividade contribui no processo de conservação da natureza, no entanto, ao perder o equilíbrio e harmonia da relação turismo com as áreas naturais, os efeitos danosos aos recursos naturais são notados.

Para Brasil (2011, p. 8) a visitação em unidades de conservação é uma forma de aproximar a sociedade e despertar o interesse em conservação da natureza, considerando a possibilidade de contato e recreação com o ambiente natural: "o turismo é capaz de dinamizar as economias locais e incrementar os recursos financeiros para manutenção de unidades de conservação".

Queiroz e Vallejo (2017, p.11) destacam que: "o uso público deve ser interpretado como estratégia de valorização social e conservação das próprias áreas protegidas" onde os gestores são responsáveis também por incentivar a valorização dos recursos naturais por parte da população.

Dessa forma, o uso público é importante e primordial para a gestão de UC, principalmente dos Parques, desde que esse uso seja racional, seguro e minimamente impactante, para isso torna-se essencial a elaboração e cumprimento do plano de manejo, normas e diretrizes que devem atingir o objetivo principal da criação dessas áreas (QUEIROZ; VALLEJO, 2017; PIRES; RUGINE, 2018).

Corroborando, Pires e Rugine (2018) destacam que também é preciso considerar a expectativa pelo o atendimento de qualidade, satisfação dos visitantes, a infraestrutura para visitação e a qualidade dos recursos ambientais pois, isso reflete na experiência vivenciada por aqueles que buscam as unidades. 
De acordo com Faraji et al., (2010) o turismo contribui com áreas naturais protegidas, pois a atração de visitantes reforça os recursos naturais como valiosos, bem como, acredita-se que o turismo tem potencial para aumentar o reconhecimento do público e espalhar a sensibilização dos problemas ambientais. Além disso, o turismo apresenta contribuição financeira direta a partir da cobrança de taxas para entradas nos parques, seja por turistas, população local, ou até mesmo operadores turísticos, sendo isso então, uma estratégia que tende a contribuir na proteção e gestão das áreas.

Para Eagles et al., (2002) o turismo se apresenta como uma possibilidade de contribuição para o melhor desenvolvimento das ANPs, mas também possui potenciais riscos para essas áreas, dessa forma, serão apresentados com base nestes autores os potenciais benefícios nas dimensões de a) oportunidades econômicas; b) proteção natural e cultural; e c) qualidade de vida; e em riscos nas dimensões: a) econômica; b) sociocultural; e c) ambiental.

Diante da perspectiva dos potenciais benefícios do turismo em áreas naturais protegidas, Eagles et al., (2002) relata que pensar no turismo dentro do contexto dessas áreas resulta em efeitos advindos de Oportunidades Econômicas, atrelados principalmente ao aumento de emprego e renda nas localidades.

Oliveira et al., (2016) apresenta contextos relevantes ao discutir a percepção de população residente em uma ANP, da categoria de Floresta Nacional, que enxerga o desenvolvimento do ecoturismo como uma possibilidade de geração de emprego e renda, e consequentemente, melhorias na qualidade de vida das comunidades locais.

Quanto aos benefícios gerados na dimensão Proteção Natural e Cultural, Eagles et al., (2002, p. 27) defende que o turismo em UC possibilita a reversão dos valores financeiros acarretados para a manutenção das áreas e "indiretamente, demonstrando o valor econômico que o turismo de área protegida pode trazer para um país ou região, ele pode construir o apoio público e político para a conservação do patrimônio natural". No ponto de vista cultural, acredita-se que os turistas por vezes, procuram experiências autênticas, sendo então possível incentivar a comunidade local a manter ou recuperar tradições, ao mesmo tempo em que enriquece a experiência dos visitantes/turistas dentro dessas áreas.

$\mathrm{Na}$ dimensão de Qualidade de Vida os autores acreditam que o turismo em áreas naturais se desenvolve para proteger o que já tem de positivo, e abordar os aspectos que precisam melhorar para as comunidades do entorno. Assim, a criação e melhoria de instalações e serviços tendem a beneficiar as condições de vida dos moradores locais.

Ao que compete à permissão para visitação nas UC, ações que potencialmente são impactantes de forma negativa estão relacionadas principalmente com o volume, a frequência de visitação e a natureza das atividades que são desenvolvidas. Além disso, existe um aspecto fundamental a ser considerado nesse contexto que é o grau de sensibilidade 
e comprometimento dos visitantes com a conservação ambiental (VALLEJO, 2013).

Ainda de acordo com Vallejo (2013) entre os impactos mais comuns derivados das visitações e atividades turísticas nas UC estão: compactação ao longo das trilhas, produção de lixo, depredações, pichações, congestionamentos, difusão de hábitos urbanos, a oferta de empregos que normalmente é temporária e não absorve a maioria dos moradores durante baixa temporada, e a perda de autenticidade e integridade quando algumas tradições culturais são comercializadas para os turistas.

Para Eagles et al., (2002) os resultados advindos da prática da atividade podem acarretar riscos para as ANPs no que compete aos aspectos econômicos, socioculturais e ambientais.

Apesar da contribuição econômica do turismo ser vista por vezes como o principal benefício responsável pelo incentivo da prática turística nas áreas protegidas, essa dimensão também pode ser convertida em alguns efeitos negativos, como aumento dos custos para os moradores locais, bem como, para a gestão desses espaços. De acordo Eagles et al., (2002) o turismo aumenta a demanda por bens, serviços e instalações, também cresce a demanda por serviços básicos, como saúde e segurança, isso resulta possivelmente em maiores encargos fiscais para a comunidade local. Os autores ainda chamam atenção para a existência de casos que os custos financeiros elevam tanto que os residentes chegam a não ter mais como viver na localidade, esses casos tendem a ocorrer em áreas em que os residentes possuem rendimentos financeiros mais baixos do que os visitantes.

Sobre os riscos socioculturais, os impactos são mais visíveis no sentido da perda da autenticidade e integridade, principalmente, quando as práticas culturais são transformadas em "mercadorias" para o turismo. Outro fator a ser considerado para Eagles et al., (2002, p. 31) é que: "um número crescente de turistas pode perturbar as atividades da comunidade e competir por locais de recreação e outros serviços. O desenvolvimento do turismo mal planejado pode levar a um maior congestionamento, lixo, vandalismo e crime".

Na dimensão ambiental é notável que os possíveis riscos refletem em elementos que englobam os diferentes aspectos da natureza (ecossistema, vegetação, água, ar, solo e animais selvagens). É relevante destacar que os impactos nessas áreas podem ser por vezes irreversíveis ou de recuperação lenta, o que causa ainda maior preocupação no sentido de ser indispensável o planejamento e gestão para o desenvolvimento do turismo em UC que permitem a visitação. Entre os principais impactos causados advindos do turismo e visitação nessas áreas Eagles et al., (2002) destaca a construção de alojamentos, centros de visitantes, infraestrutura de outros serviços que tem impacto direto no meio ambiente.

Em virtude da multidisciplinaridade e abrangência das discussões sobre turismo é compreensivo que o mesmo traga consigo diferentes abordagens e facetas, onde perpassam por aspectos consideravelmente 
contribuintes para as localidades que conseguem desenvolver essa atividade, mas ao mesmo tempo, se não planejado e gerido corretamente danos e prejuízos podem ser irreparáveis.

Faraji et al., (2010, p. 4) diz que apesar do turismo e o meio ambiente em diversas situações parecerem "inimigos", esses podem ser dois "amigos próximos", porém, para isso: "precisa-se planejar corretamente e ter a cooperação de todas as outras organizações ou indústrias que estão relacionadas ao turismo, direta e indiretamente".

Dessa forma, Queiroz e Vallejo (2017) destacam a importância da gestão dessas áreas, sendo primordial considerar as relações existentes nesses espaços, ou seja, a interação humana no contexto ambiental, buscando equacionar possíveis conflitos da visitação e preservação dos recursos naturais.

Nessa perspectiva, entende-se que no turismo, assim como em demais atividades, o planejamento se faz indispensável, tendo em vista que, necessita-se buscar equilibrar e ordenar as ações e relações existentes nos âmbitos econômicos, sociais, culturais e ambientais.

Mesmo entendendo que o planejamento não é a solução para todos os problemas que envolvem o desenvolvimento do turismo, sabe-se que esse instrumento pode contribuir de forma significativa nesse contexto, principalmente se o processo for integrativo e participativo envolvendo os diferentes atores interessados na atividade.

Nessa abordagem do planejamento turístico em áreas naturais protegidas, de acordo com Eagles et al., (2002, p. 41) "acima de tudo, é essencial que todas as partes interessadas estejam adequadamente envolvidas no processo".

Corroborando, Sonaglio (2003) acredita que é necessário o envolvimento de ambientalistas, academia, representantes de órgãos públicos do turismo, empresários e as comunidades receptoras no processo de determinação do que se pretende desenvolver quanto ao turismo em áreas naturais, antes da tomada de decisões para implementações de equipamentos e atividades.

Jiménez et al., (2017) discutem sobre a efetividade de conservação do Parque Nacional de Cabo Pulmo (PNCP), no México, onde após seu decreto de criação (1995) houve um aumento significativo (acima de 400\%) da sua biomassa. Para os autores o planejamento e políticas implementadas contaram com a participação de: a) esforços do governo federal e estadual; b) participação de acadêmicos com pesquisas; c) organizações civis; e d) compromisso e vontade da população local. Destaca-se que nos resultados apresentados o fator com maior expressividade de determinação para funcionamento da política de criação e gestão dessa ANP é a participação e apropriação da comunidade respeitando e colaborando com as leis ali implementadas.

Nesse contexto, o estudo de Hernández et al., (2018) destaca a necessidade de considerar a heterogeneidade da estrutura local, essencialmente na forma de administração e gestão das ANP. Em uma 
gestão por parte da população local pautada na cooperatividade, os autores identificaram contrastes entre as próprias organizações, onde em alguns casos os membros não sabem ler e escrever, enquanto outras organizações possuem parceiros especialistas em áreas de gestão e administração. Além disso, são discutidos os conflitos gerados pelos os interesses divergentes entre os atores da conservação da biodiversidade e as populações locais.

Dessa forma, entende-se que assim como no planejamento turístico voltado para destinos, nas áreas de conservação ambiental o envolvimento participativo das partes interessadas é relevante para garantir que as tomadas de decisões não se concentrem apenas em um ator.

Sonaglio (2003, p. 62) pontua que ao se tratar de áreas naturais protegidas e o turismo: "há necessidade de interação e gestão compartilhada para o planejamento da atividade que envolve tanto o ambiente, quanto as comunidades receptoras e do entorno".

De acordo com Oliveira et al., (2016) a inserção da própria população local no processo de planejamento para uso da UC é fundamental, pois, possibilita identificar impactos causados pela sua ação (atual e futura) e atividades potenciais nas áreas protegidas, observando seus objetivos de criação e as características locais.

No contexto do turismo, esse planejamento de maneira participativa e integrativa é incentivada pela política nacional do turismo, principalmente no contexto do Programa de Regionalização, lançado no ano de 2004, sua execução previa a formulação de institucionalização de instâncias de governança regional que é definida por Brasil (2007, p. 16) como: "uma organização com participação do Poder Público e dos atores privados dos municípios componentes das regiões turísticas, com o papel de coordenar o Programa em âmbito regional'.

Sobre a relevância e papel das instâncias de governança regional para a gestão e planejamento do turismo, Rodrigues e Souza (2016) acreditam que a regionalização turística tem o papel de proporcionar uma estruturação da gestão do turismo e de mediar o processo de planejamento local pautado nas políticas e ações a nível federal.

Nesse sentido, entende-se que as instâncias de governança regional, responsáveis pelo planejamento turístico considerando a realidade regional, devem realizar discussões de forma a contribuir no processo de criação de novos áreas que possuam relação com o desenvolvimento do turismo, sendo primordial então, investigações sobre os debates realizados nesse âmbito.

No RN essas instâncias são denominadas de Polos Turísticos, sendo estes: Polo Agreste-Trairí (15 municípios integrantes), Polo Costa Branca (17 municípios integrantes), Polo Seridó (12 municípios integrantes), Polo Serrano (20 municípios integrantes) e Polo Costa das Dunas (15 municípios integrantes).

O Polo Costa das Dunas possui nos recursos naturais e unidades de conservação alguns dos principais atrativos dessa região, onde de acordo com o SETUR/RN (2011, p.140) "praticamente todas as Unidades de 
Conservação e áreas potenciais do Polo, são exploradas turisticamente", o que reforça a contribuição significativa dessas áreas para o desenvolvimento do turismo no polo.

Diante disso, é reforçada a ideia de que o turismo é uma atividade que tende a contribuir no desenvolvimento das UC, porém, para isso, é preciso um planejamento voltado para os aspectos de visitação que abarque a integração e participação dos atores interessados na prática do turismo nessas áreas.

\section{Material e métodos}

\section{Caracterização da área de estudo}

O Instituto de Desenvolvimento Sustentável e Meio Ambiente IDEMA é um órgão que entre suas atribuições é contemplado o processo de implantação de Unidades de Conservação. O Rio Grande do Norte possui 10 UC instituídas a nível estadual, e quatro em processo de criação, uma Área de Proteção Ambiental (Carnaúbas), um monumento natural (Cavernas de Martins) e dois Parques Estaduais (Mangues e Jiqui).

O Parque Estadual Mangues do Potengi situa-se na cidade de Natal/RN, abrange uma área de 824,43 hectares, localiza-se com área em dois bairros da Zona Norte: Salina, que possui 1.177 residentes e Redinha com 16.630, dados do Censo 2010 do IBGE. A criação do Parque Mangues do Potengi foi aprovada pelo Conselho Municipal de Meio Ambiente CONEMA, no ano de 2006, alegando principalmente a importância de recuperação e conservação do Mangue e Rio Potengi, pois o nível de degradação e poluição no local prejudica o ecossistema e compromete 0 local.

O Parque Estadual do Jiqui, localiza-se de forma integral no município de Parnamirim de forma mais específica no bairro Parque do Jiqui, que de acordo com o Censo 2010 do IBGE compreende uma população residente de 1.636 habitantes.

A área possui predominante paisagem composta por Mata Atlântica, e potencial hídrico como o Rio Pitimbu, Taborda e Lagoa do Jiqui. O apelo do Jiqui consiste principalmente na degradação e poluição trazida pelo crescimento da cidade de Natal/RN aos recursos hídricos da localidade, como é o caso da Lagoa do Jiqui e Rios Pitimbu e Taborda.

Apesar das áreas não possuírem atratividade considerável para visitação antes da criação dos parques, a questão do turismo e visitação é pensada em virtude do diferencial paisagístico do local, onde potencialmente os PEMAP e PEJ seriam atrativos com proposta que se distancia do turismo de sol e praia predominantemente ofertada no litoral potiguar.

Os Planos Emergenciais de ambos os parques realizados em 2009 têm como objetivo principal a conservação dos recursos naturais e 0 estabelecimento de parâmetros estratégicos que possibilitem a realização de pesquisas científicas, atividades de educação ambiental e turismo ecológico. Além disso, os planos apresentam ações de emergências que fornecem 
subsídios para criação de condições para o desenvolvimento dessas atividades com estruturas que possam atender as necessidades mínimas dos visitantes, e esses aspectos devem contar ainda com o planejamento participativo com envolvimento da comunidade local em todo o processo.

Tendo em vista a abordagem do turismo no contexto de criação das unidades de conservação já citadas, na figura 1 é possível notar que as duas UC em criação na região se encontram dentro do Polo Turístico Costa das Dunas o que reforça a necessidade de investigação sobre discussões acerca da criação dessas novas áreas que potencialmente podem contribuir com o desenvolvimento do turismo regional.

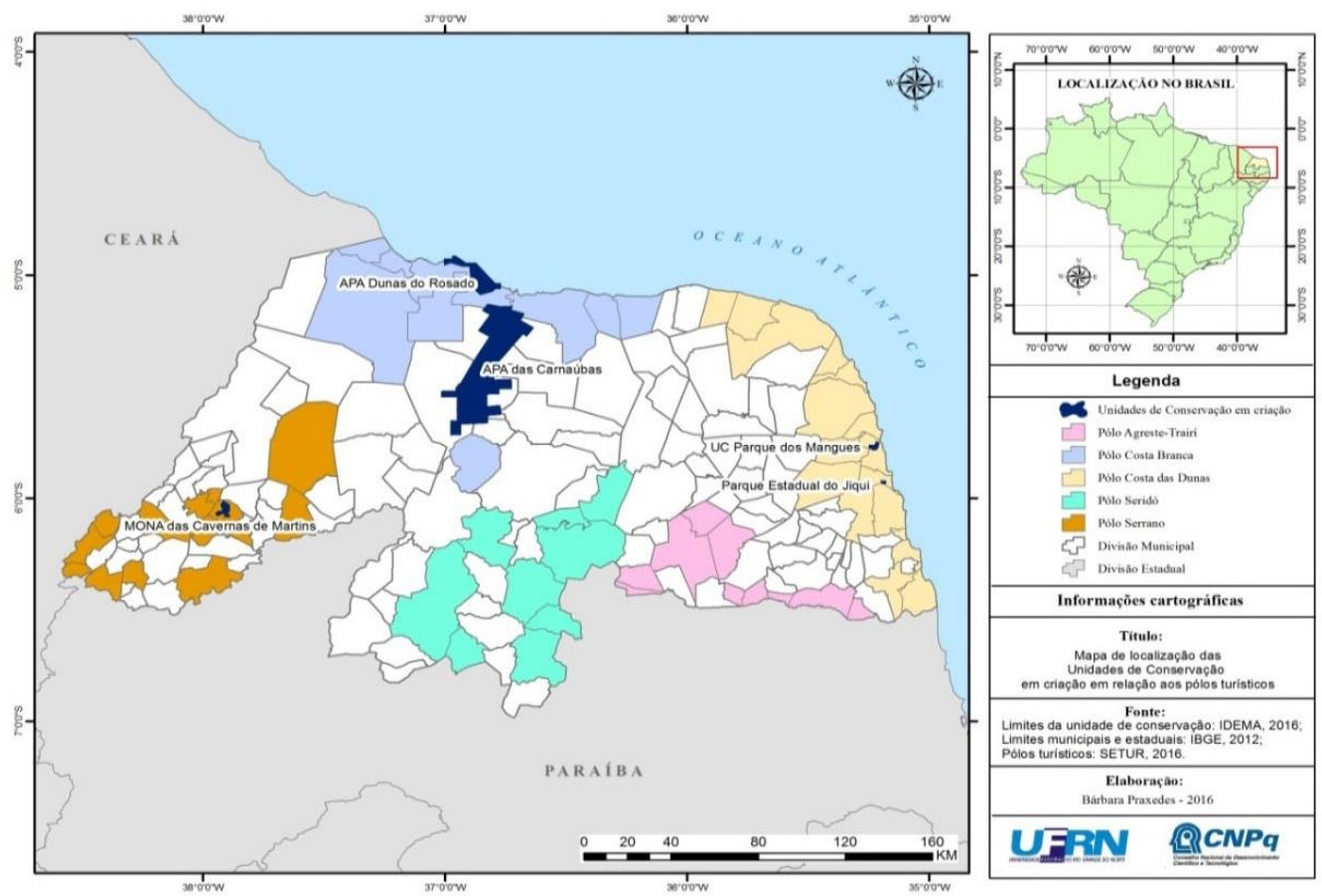

Figura 1: Mapa Polos turísticos e Unidades de Conservação em criação.

Figure 1: Map tourist centers and conservation units in creation.

Fonte: Projeto de pesquisa - UFRN/CNPq, 2016.

Source: research project - UFRN/CNPq, 2016.

O Polo Costa das Dunas contempla 15 municípios, sendo eles: Baía Formosa, Canguaretama, Ceará-Mirim, Extremoz, Maxaranguape, Natal, Nísia Floresta, Parnamirim, Pedra Grande, Rio do Fogo, São Gonçalo do Amarante, São Miguel do Gostoso, Tibau do Sul, Touros e Vila Flor (MINISTÉRIO DO TURISMO, 2020).

Já a instância de governança, de acordo com a Secretaria Executiva do Polo entre seus conselheiros titulares e suplentes para gestão de 2017 a 2020, é constituída por 36 instituições representadas, com 36 conselheiros titulares e seus respectivos suplentes. 


\section{Procedimentos metodológicos}

Quanto aos procedimentos metodológicos é pertinente destacar que o trabalho possui caráter exploratório e descritivo, além disso, a abordagem da pesquisa é qualitativa que de acordo com Veal (2011) envolve a coleta de uma grande quantidade de informações, porém, sobre um pequeno número de pessoas, e os resultados são apresentados e discutidos considerando maior captação de informações de maneira mais aprofundada sobre determinados temas.

A pesquisa bibliográfica faz parte de todo o processo de construção do presente estudo, uma vez que é pertinente o conhecimento e leitura de obras que abordem aspectos relacionados ao trabalho para uma fundamentação teórica consistente.

A pesquisa documental também fez parte do processo de construção da pesquisa, pois leva-se em consideração que esse tipo de investigação, de acordo com Gil (2008), está relacionado a materiais que ainda não receberam tratamento analítico constituídos de fontes documentais. Dessa forma, foram analisados documentos relacionados às UC que estão em criação.

Inicialmente foi realizada pesquisa e análise documental principalmente relacionado aos processos de criação das UC e em seguida os resultados são apresentados de forma descritiva e em quadros. Além disso, foi feita uma pesquisa documental com base em 38 atas de reuniões do Polo Turístico Costa das Dunas (repassadas após solicitação a secretaria executiva do Polo) compreendendo o período de 2006 - 2017, sobretudo, explica-se a escolha do período em virtude do processo de criação das UC ter iniciado em 2006. Dessa forma, na perspectiva de averiguar a existência de discussões voltadas para a criação das UC que se encontram dentro de municípios que fazem parte do Polo e também são de categoria que incentiva o uso turístico e visitação.

Ressalta-se ainda que, na presente pesquisa são apresentados resultados construídos a partir da análise de conteúdo de uma entrevista semiestruturada, aplicada em primeiro de novembro de 2017, com a coordenação do NUC - IDEMA/RN, com objetivo de identificar a atual fase, envolvimento de atores ligados ao turismo e também o planejamento vinculado ao desenvolvimento da atividade turística em ambos os parques em criação.

\section{Resultados e discussões}

\section{O processo de criação dos Parques Mangues do Potengi e Jiqui.}

As UC são espaços relevantes na conservação de elementos da biodiversidade podendo apresentar benefícios ambientais, socioculturais e econômicos para as localidades do entorno. No Brasil, os números são expressivos de áreas já instituídas, totalizando de acordo com o CNUC (2020) em 2.446 unidades no País, nas diferentes categorias e esferas. 
No RN, são dez UC criadas, destacando que no litoral potiguar concentra-se maior parte dessas áreas com seis unidades, além das UC existentes, o IDEMA está investindo na criação de mais quatro unidades, sendo estas: APA das Caraúbas, MONA das Cavernas de Martins, Parque dos Mangues e o Parque Estadual do Jiqui. Destes, Mangues e Jiqui estão localizados no Polo Turístico Costa das Dunas e constituem o objeto da presente pesquisa.

Ao que se refere as UC em criação no Polo realizou-se análise documental do processo em andamento das áreas, observando quatro principais aspectos: a) demanda de criação; b) principais documentos do processo; c) entraves para continuidade do processo; d) fase atual do processo, como pode ser visto no quadro 2 (PEJ) e quadro 3 (PEMAP).

Quadro 2: Processo de criação do Parque Estadual do Jiqui.

Frame 2: Proceso de creación del parque Estadual de Jiqui.

\begin{tabular}{|c|c|c|}
\hline \multirow{11}{*}{ 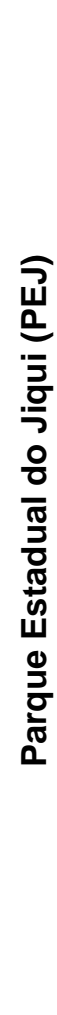 } & \multicolumn{2}{|c|}{ Demanda para a criação: } \\
\hline & \\
\hline & \multicolumn{2}{|c|}{ Principais documentos referentes ao processo: } \\
\hline & $\begin{array}{l}\text { a)Quadragésima Sétima Reunião } \\
\text { Ordinária do Conselho Estadual do } \\
\text { Meio Ambienta - CONEMA, no dia } \\
10 \text { de outubro de 2006; }\end{array}$ & $\begin{array}{l}\mathrm{Na} \text { ocasião foi realizada a apresentação e } \\
\text { apreciação da proposta de criação do parque. }\end{array}$ \\
\hline & $\begin{array}{l}\text { b) Plano de Ação Emergencial para o } \\
\text { Parque do Jiqui, } 2009 \text {. }\end{array}$ & $\begin{array}{l}\text { São apresentados os contextos de localização da } \\
\text { área, sua importância ambiental, características do } \\
\text { meio biológico, físico e as principais ações } \\
\text { emergências necessárias. }\end{array}$ \\
\hline & $\begin{array}{l}\text { c)Minuta de Criação do Parque Estadual } \\
\text { do Jiqui - PEJ, } 2011 .\end{array}$ & $\begin{array}{l}\text { Apresenta-se um esboço dos objetivos, delimitações } \\
\text { de zonas, aspectos de gestão do Parque. }\end{array}$ \\
\hline & d)Ofícios, despachos e atas. & Mostram os desdobramentos do processo. \\
\hline & \multicolumn{2}{|c|}{ Principais entraves para continuidade do processo: } \\
\hline & \multicolumn{2}{|c|}{$\begin{array}{l}\text { Após solicitações da Consultoria Geral do Estado - CGE, os principais entraves para } \\
\text { continuidade do processo estão ligados a: a) consulta pública realizada com base nas normas } \\
\text { estabelecidas no SNUC (2000); b) é questionada a guarda provisória da área referente ao } \\
\text { parque, que nos documentos apresentados ao CGE ainda não possuía definitivamente ao } \\
\text { Estado. }\end{array}$} \\
\hline & \multicolumn{2}{|c|}{ Fase atual do processo: } \\
\hline & \multicolumn{2}{|c|}{$\begin{array}{l}\text { Com base na entrevista realizada em } 01 \text { de novembro de } 2017 \text {, na coordenação do NUC, é } \\
\text { possível afirmar que o processo se encontra parado e dependendo principalmente da cessão } \\
\text { da área do Parque do Jiqui por parte da Superintendência do Patrimônio da União - SPU. }\end{array}$} \\
\hline
\end{tabular}

Fonte: dados da pesquisa, 2018.

Source: datos de la encuesta, 2018.

O Quadro 2 apresenta os principais passos e processos existentes na criação ainda em andamento do PEJ. Nota-se que o apelo e demanda de criação ocorre na perspectiva de proteção de elementos naturais, mas que também se destacam as atividades como o ecoturismo, pesquisa e educação ambiental. Os principais documentos descritivos de características da área, delimitação de objetivos do parque, consistem em ser: Plano de Ação Emergencial, em 2009, e a Minuta de Criação, em 2011. 
Sobre o andamento do processo, pode-se afirmar que a partir do encaminhamento para a Consultoria Geral do Estado - CGE, em 24 de novembro de 2011, houveram cinco principais recomendações para adoção por parte do IDEMA: I) atender previamente o pressuposto formal da consulta pública; II) viabilizar o pronunciamento do Diretor Presidente da Empresa de Pesquisa Agropecuária do Rio Grande do Norte (EMPARN), já que esta empresa é cessionária do Parque; III) pronunciamento da Superintendência do Patrimônio da União do Estado (SPU/RN), pois a área que será criada faz parte do patrimônio da união; IV) o assunto precisaria ser submetido à Procuradoria Geral do Estado (PGE), por intermédio de sua Procuradoria do Patrimônio e da Defesa Ambiental (PPDA); e V) é solicitado a obtenção de manifestação da diretoria geral e da assessoria jurídica do próprio IDEMA/RN.

O IDEMA realizou esforços para o cumprimento das solicitações feitas pelo CGE a fim de viabilizar o seguimento do processo de criação do PEJ, todas as ações foram realizadas no ano de 2012, concentradas nos meses de abril e maio.

No entanto, ao que se refere a entraves para continuidade e avanço do processo de criação, apesar da realização das atividades nota-se dois procedimentos questionados pelo CGE, o primeiro trata-se do termo de Guarda Provisória referente à área do futuro Parque, onde é sugerido o aguardo do IDEMA ao desfecho do Processo Administrativo, por uma questão de segurança jurídica. O segundo é a respeito da consulta pública realizada, que de acordo com CGE a divulgação não ocorreu de maneira recomendável diante da complexidade da criação do PEJ, pois houve apenas a fixação de um cartaz no mural de avisos do próprio Condomínio Esplanada.

Com base na entrevista realizada em 01 de novembro de 2017 na coordenação do NUC afirma-se que o processo se encontra parado e dependendo da cessão da área do Parque do Jiqui, por parte do SPU. Além disso, ressalta-se que o NUC acredita que mesmo após a cessão da área, o processo pode ser lento, pois os estudos técnicos e a consulta pública já são considerados, de certo modo, desatualizados em virtude da demora em criação da UC, o que também pode gerar possíveis atrasos nas instâncias cabíveis para a implementação da área.

Sobre o PEMAP, o Quadro 3 (próxima página) apresenta os principais passos e elementos que envolvem sua criação, bem como, os entraves para continuidade do processo, e sua atual fase.

O apelo para criação do PEMAP também é voltado para a proteção de elementos naturais que estão sofrendo com elevada degradação e poluição. Nota-se ainda uma preocupação com manutenção e organização de atividades econômicas já desenvolvidas na área, como a questão da carcinicultura. Sobre os principais documentos que encaminham esse processo, assim como no PEJ, o Plano Emergencial em 2009 e a Minuta de Criação cumprem com o papel de descrição da área do Parque, bem como, os principais objetivos da proposta de instituição da UC. No entanto, a 
Consulta Pública realizada para o PEMAP em 2015 apresenta elementos mais representativos e que enquadram-se nas diretrizes para tal ação.

Quadro 3: Processo de criação do Parque Estadual Mangues do Potengi.

Frame 3: Proceso de creación del Parque Estadual Mangues de Potengi.

\begin{tabular}{|c|c|c|}
\hline \multirow{12}{*}{ 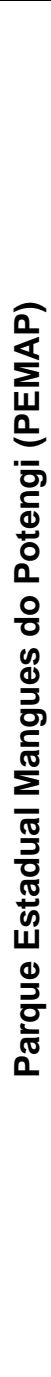 } & \multicolumn{2}{|c|}{ Demanda para a criação: } \\
\hline & \multicolumn{2}{|c|}{$\begin{array}{l}\text { Apresentada com base na necessidade de proteção e conservação das formações } \\
\text { naturais do litoral, sítios naturais raros e com beleza cênica, bem como, considera-se a } \\
\text { relevância da área dos mangues do Rio Potengi, ecossistema importante para a vida } \\
\text { marinha e depurador de águas fluviais, que encontra-se com elevada degradação. Há } \\
\text { preocupação com manutenção de atividades econômicas na área, principalmente } \\
\text { atreladas à carcinicultura. }\end{array}$} \\
\hline & \multicolumn{2}{|c|}{ Principais documentos referentes ao processo: } \\
\hline & $\begin{array}{l}\text { a)Quarta Décima Reunião } \\
\text { Extraordinária do CONEMA, } \\
\text { em } 19 \text { de Abril de 2006; }\end{array}$ & $\begin{array}{l}\text { Na ocasião foi realizada a apresentação e apreciação } \\
\text { da proposta de criação do parque. }\end{array}$ \\
\hline & $\begin{array}{l}\text { b)Plano de Ação Emergencial para } \\
\text { o Parque do Jiqui, 2009; }\end{array}$ & $\begin{array}{l}\text { São apresentados os contextos de localização da } \\
\text { área, sua importância ambiental, características do } \\
\text { meio biológico, físico e as principais ações } \\
\text { emergências necessárias. }\end{array}$ \\
\hline & $\begin{array}{l}\text { c) Minuta de Criação do Parque, } \\
2009 ;\end{array}$ & $\begin{array}{l}\text { Apresenta-se um esboço dos objetivos, delimitações } \\
\text { de zonas, aspectos de gestão do Parque. }\end{array}$ \\
\hline & d)Ata da Consulta Pública, 2015. & $\begin{array}{l}\text { Na consulta, após apresentação da proposta e do } \\
\text { projeto arquitetônico do IDEMA, foram levantadas } \\
\text { diferentes questões, relacionadas à delimitação da } \\
\text { área, uso turístico, recuperação do mangues, e sobre } \\
\text { a categoria da UC, sendo delimitados XV } \\
\text { encaminhamentos para análise por parte do IDEMA. }\end{array}$ \\
\hline & e)Ofícios, despachos e atas. & Mostram os desdobramentos do processo. \\
\hline & \multicolumn{2}{|c|}{ Principais entraves para continuidade do processo: } \\
\hline & \multicolumn{2}{|c|}{$\begin{array}{l}\text { O processo foi perdido e retornou a caminhar no ano de } 2015 \text {, dificultando o avanço de } \\
\text { forma mais rápida. Também interferiu os avanços, o estudo socioeconômico, que apesar } \\
\text { do termo de referência feito pelo IDEMA, nenhuma instituição atendeu os requisitos para } \\
\text { tal realização. }\end{array}$} \\
\hline & \multicolumn{2}{|c|}{ Fase atual do processo: } \\
\hline & \multicolumn{2}{|c|}{$\begin{array}{l}\text { Com base na entrevista realizada em } 01 \text { de novembro de } 2017 \text { com o NUC, foi possível a } \\
\text { compreensão da atual situação referente à criação do PEMAP, que não avançou após a } \\
\text { consulta pública, e ainda depende da realização de estudos socioeconômicos. }\end{array}$} \\
\hline
\end{tabular}

Fonte: dados da pesquisa, 2018.

Source: Datos de la Encuesta, 2018.

No cenário de entraves para continuidade de criação da UC, por meio do acervo documental disponibilizado pelo IDEMA, é possível afirmar que o físico do processo administrativo referente à Criação da UC Parque dos Mangues foi perdido, sendo solicitado em 10 de julho de 2013 pela chefia do gabinete da instituição a busca de tal processo em todos os setores, não obtendo sucesso. Cabe ressaltar, que o IDEMA foi condenado a reparar o dano causado em toda a área do Manguezal (atrelados principalmente a atividade de carcinicultura) em que este processo foi julgado em 2007 e em 2013 estava em status de execução da sentença. 
É nesse contexto que no dia 22 de julho de 2013 é aberto o processo administrativo de restauração a fim de recuperar o processo relacionado a criação do PEMAP, sendo também solicitado todos os documentos referentes à criação da UC que encontram-se nos arquivos do IDEMA, além disso, o NUC sugere três encaminhamentos na busca pelos pressupostos necessários à criação de uma UC, sendo estes: 1) realização de estudos preliminares à criação de $U C ; 2$ ) realização de consulta aos órgãos interessados na viabilidade da criação; e 3) realização da consulta pública prévia, nos termos do art. 5ำ do Decreto Federal n $4.340 / 02$.

Constata-se que o processo volta a caminhar apenas no ano de 2015, principalmente com a realização de uma consulta pública, elaboração de mapas de limite e delimitação do PEMAP e a busca por informações referentes à situação de empreendimentos licenciados na área do Rio Potengi, nos limites propostos para a criação da UC.

Com base nos documentos repassados pelo IDEMA a Ação Civil Pública foi o último andamento do processo da criação do PEMAP. Dessa forma, realizou-se uma entrevista realizada em 01 de novembro de 2017 com o NUC, em que foi possível a compreensão da atual situação referente à criação do PEMAP:

[NUC] O que, o Parque do Mangues do Pontegi, ele está, depois da audiência pública, o que a gente fez foi um termo de referência para contratação de um estudo socioeconômico na área, certo? Só que ai ficou na fase de levantamento de possíveis instituições que façam esse estudo. Então, ficou nesse pé o processo aqui no IDEMA. Mas com relação à criação mesmo, ele não avançou depois da audiência pública.

Com base na afirmação acima, percebe-se que assim como no PEJ o processo para criação do PEMAP também se encontra parado e tem como principal ação pendente para continuidade no processo a contratação de empresas para realização de estudo socioeconômico na área. Além disso, comentou-se na entrevista a relevância do estudo socioeconômico, pois, esse será determinante também para a delimitação da questão de área de uso público, das atividades econômicas desenvolvidas na UC e até mesmo a própria categoria adequada para essa unidade.

Considerando a descrição do processo de criação de UC do Polo Costa das Dunas percebe-se que apesar de se tratar de parques, nas UC que ainda passam por esse processo, existe uma influência ainda tímida na perspectiva do turismo, em que são singelas as abordagens de poder de atração nas áreas. Dessa forma, o objetivo da entrevista com o NUC também foi identificar o que está sendo planejado em relação a atividades voltadas para o turismo nessas áreas. 
De acordo com as respostas da entrevista realizada com o NUC pode-se destacar algumas falas relevantes para o contexto do turismo nas UC em criação PEMAP e PEJ:

[NUC] Quanto ao turismo, assim, efetivamente até o momento não tem nada previsto.

[NUC] Não tem ainda se planejado para o turismo. $O$ objetivo é a questão dos corpos d'águas e do manguezal, ainda não tem essa questão do turismo, como por exemplo, na criação dos recifes dos corais, dunas do rosado, o viés do turismo.

[NUC] Lembro que na audiência foi falado em revitalizar o Museu, e o centro de visitação, no mangue tem a proposta de centro de visitação. É porque já se existia essa ideia, mas não envolvendo um parque, independente da unidade de conservação. Queria envolver os dois, se for Parque, utilizar aquela área como de uso público.

Nesta prisma, percebe-se que as questões referentes a atividades voltadas para visitantes e turistas ainda não estão sendo discutidas e planejadas nessa fase do processo de criação, mesmo se tratando da categoria de Parque e sendo visto em alguns momentos da construção desta pesquisa a presença de justificativa dessas áreas como potenciais para o turismo e visitação, como, por exemplo, durante a consulta pública (PEMAP) onde alguns participantes comentam que a atividade turística pode contribuir no processo de desenvolvimento sustentável nessas áreas.

Ainda sobre o planejamento de atividades e infraestruturas voltadas para a demanda visitante e turista, nota-se apenas o centro de visitação e o Museu do Mangues foi citado, já referente ao PEJ não se tem discussão sobre nenhum aspecto de atividades ou infraestrutura a serem desenvolvidas na área.

Sobre os possíveis impactos negativos do turismo e visitação nas áreas em criação, o NUC acredita em dois principais aspectos para minimização desses efeitos, o primeiro refere-se ao estudo socioeconômico que irá realizar um diagnóstico sobre o PEMAP trazendo algumas ações e estratégias serão sinalizadas, como depósito de lixo, áreas de uso público, ordenamento do solo entre outros. Já o segundo instrumento relatado como responsável pela minimização de impactos negativos derivados do turismo e da visitação no PEJ e PEMAP é o Plano de Manejo, que deve ser elaborado após a criação das UC e trará direcionamentos indispensáveis para a realização das atividades com menores danos possíveis. 


\section{A abordagem do turismo no processo de criação dos Parques Estaduais Mangues do Potengi/RN e Jiqui (RN).}

Compreende-se que para maior possibilidade de um planejamento turístico eficaz é necessário a participação e envolvimento de diferentes atores nesse processo, dessa forma, como objetivo específico do presente trabalho buscou-se identificar atores que estão contribuindo no planejamento do turismo no contexto das UC em criação no Polo Costa das Dunas.

Inicialmente, foram analisados documentos relacionados às consultas públicas referentes aos dois parques em criação, Mangues do Potengi e Jiqui. Sendo assim, optou-se por apresentar informações desse cenário com dois aspectos, a instituição representada e as observações realizadas em relação ao turismo nestas UC.

Relativo à Consulta Pública que trata sobre a criação do Parque do Jiqui, realizada em 24 de maio de 2012, pode-se perceber que não estavam presentes representantes de instituições públicas nem privadas relacionadas diretamente ao desenvolvimento da atividade turística.

A partir da análise da ata referente à consulta pública do Parque do Jiqui, é possível constatar que não houve participação de nenhuma instância relacionada ao planejamento ou gestão do turismo em qualquer esfera de governo e do setor privado, podendo isto ter ocorrido por diferentes razões, como a falta de interesse pela discussão, já que a área não possui um relevante interesse turístico atualmente, ou até mesmo pela falta de convite e divulgação voltados para esses atores. Além disso, nesta audiência, não aconteceram discussões ou observações referentes ao desenvolvimento da atividade turística nesta UC.

No Parque dos Mangues do Potengi, também foi realizada uma consulta pública no ano de 2015. Nesta, pode-se perceber uma maior discussão e maior presença e participação de diferentes atores, no Quadro 4 (próxima página), com base na ata da audiência, destaca-se alguns membros presentes, e observações referentes ao turismo nessa UC.

Nesta perspectiva, ressalta-se a presença de uma instância relevante ao processo de planejamento do turismo no Estado do RN, a Secretaria Estadual de Turismo, no entanto, nenhuma observação foi realizada pelo seu representante.

Apesar da relevância e contribuição do turismo dentro do Parque ser destacada pela procuradoria do Estado, justificando isso, por meio do potencial turístico existente no lugar, e acreditando que o turismo ecológico pode contribuir na perspectiva sustentável na área, alguns presentes fizeram observações e contestações referentes à prática do turismo que é planejada ser desenvolvida dentro do Parque. 
Quadro 4: Atores e participação no planejamento do turismo nos Mangues do Potengi.

Frame 4: Actores y participación en la planificación turística em Mangues do Potengi.

\begin{tabular}{|c|c|}
\hline $\begin{array}{l}\text { Instituições } \\
\text { representadas }\end{array}$ & Observações vinculadas ao turismo na UC \\
\hline Procuradora do Estado & $\begin{array}{l}\text { Os aspectos cênicos e paisagístico do Parque do Mangues } \\
\text { revelam o potencial turístico da área. Destaca a atividade } \\
\text { turística como econômica e o caminho para o } \\
\text { desenvolvimento sustentável pautado no turismo ecológico }\end{array}$ \\
\hline Coordenador do NUC & $\begin{array}{l}\text { Apresentação do projeto de criação que prevê uso público e } \\
\text { visitação turística. }\end{array}$ \\
\hline $\begin{array}{l}\text { Arquiteto e professor do } \\
\text { curso de Arquitetura da } \\
\text { UFRN }\end{array}$ & $\begin{array}{l}\text { Ressalta a importância do mangues e da sua recuperação } \\
\text { das áreas devastadas pela carcinicultura do Rio Potengi, a fim } \\
\text { de proporcionar e promover o turismo ecológico. O } \\
\text { representante é o responsável pela elaboração do anteprojeto } \\
\text { do centro de visitação turística, que sugere que a instalação } \\
\text { de equipamentos para visitação turística fosse utilizada de } \\
\text { madeira certificada ou de reflorestamento, e ainda explicou } \\
\text { que toda a arquitetura será sustentável. }\end{array}$ \\
\hline Promotoria de Justiça & $\begin{array}{l}\text { Ressaltou o pedido do Ministério Público foi de tirar qualquer } \\
\text { edificação que impactasse os manguezais, mas questiona-se } \\
\text { como o IDEMA propõe a instalação de museus. Afirma que o } \\
\text { fundamental é proteger o manguezal, mas concorda que o } \\
\text { turismo pode ser desenvolvido na área, mas com cuidado } \\
\text { para não agredir o ecossistema. }\end{array}$ \\
\hline Ambientalista & $\begin{array}{l}\text { Discordou da instalação de equipamentos apresentados no } \\
\text { projeto. }\end{array}$ \\
\hline Morador de Natal & $\begin{array}{l}\text { Questionou a escolha da categoria do Parque, que impede a } \\
\text { sociedade em muitos aspectos, destacando que é possível } \\
\text { que ocorra o processo de elitização dos parques, afastando a } \\
\text { população tradicional. }\end{array}$ \\
\hline
\end{tabular}

Fonte: autoria própria, 2017.

Source: Autoría propia, 2017.

Alguns casos citados na reunião: um ambientalista, que discordou da criação de equipamentos no espaço, acreditando que isso irá trazer danos e prejuízos ambientais; um participante morador de Natal, que questiona a categoria de Parques que incentivam a visitação e o turismo, o que pode resultar na elitização desses parques, afastando assim a população; A representação da Promotoria de Justiça ressalta o cuidado com a proposta de instalações a fim de atender a esses visitantes, pois a própria solicitação do Ministério Público foi de retirada de qualquer edificação que impactasse os manguezais, concordando com o turismo no local, sem agressão ao ecossistema. Participante arquiteto e professor da UFRN, acredita na importância de recuperação dos mangues, até mesmo para o turismo na área, e ressalta que o madeira que se pretende utilizar para as instalações e equipamentos é certificada e de reflorestamento, buscando uma estrutura sustentável para atender a demanda visitante.

Nota-se que nesta consulta pública houve observações vinculadas ao turismo, tanto quanto em malefícios, atrelados principalmente aos impactos ambientais derivados da construção de infraestruturas e equipamentos para atender a demanda visitante. Além disso, percebe-se um conflito social incipiente, em que na ótica de um morador é citada a possível elitização da UC resultando no afastamento da população local. No entanto, o turismo 
também é visto por alguns atores como uma atividade que pode contribuir e potencializar a economia do local, bem como, no desenvolvimento mais sustentável na área.

Acreditando que é relevante a participação e envolvimento de instâncias de governança, bem como, atores de instituições pública e privadas responsáveis pelo planejamento e gestão do turismo neste contexto de criação de Parques que trazem em sua proposta o incentivo ao desenvolvimento do turismo nestas áreas, buscou-se a coordenação do NUC a fim de identificar se esse envolvimento está ou não ocorrendo.

Dessa forma, realizou-se uma entrevista com NUC (1 de novembro de 2017) a fim de saber se as comunidades no entorno foram consultadas sobre a questão do uso público e turístico das áreas, bem como, averiguar a existência de parcerias públicas e/ou privadas com as instâncias responsáveis pela gestão e planejamento do turismo, ou até mesmo com empresas interessadas na realização do turismo no Parque do Jiqui.

Inicialmente, foi questionado se houve consulta às comunidades sobre o uso turístico das áreas onde os parques estão sendo criados, pois, um dos principais problemas quanto à criação de UC do Polo estão atrelados aos conflitos com os residentes do entorno desses locais. Dessa forma, de acordo com o NUC a participação e consulta a essas comunidades foi realizada até o momento só nas consultas públicas já observadas neste trabalho.

[NUC] A gente vê que elas já estão participando nas audiências, com os representantes, de ONGs de Associações, que eles estão nas audiências já para discutir a possibilidade de ser uma unidade de conservação, daí para o processo de criação vai ter as consultas públicas diretas, e oficiais e necessárias para a criação.

Apesar de não ter se realizado ainda as consultas diretas com as comunidades no entorno, avanço do processo prevê, de acordo com o NUC, a pretensão de entrevistá-los a fim de realizar um diagnóstico, entender o uso que essas pessoas pretendem dar a UC e como elas veem a questão fundiária, categoria e o uso público. Ressalta-se que o NUC informou que essa questão da consulta direta sobre o turismo e uso público é a mesma situação em ambos os Parques em criação.

Em se tratando especificamente das parcerias públicas e privadas com o setor do turismo e o envolvimento do Polo Costa das Dunas nesse processo de planejamento do turismo nas UC em criação, algumas falas da entrevista com o NUC (1 de novembro de 2017) devem ser destacadas: 
[NUC] Se você for ver, o turismo acontece na maioria das unidades de conservação, nas APAs que são de maiores extensões, só que assim, não é aquele turismo para a unidade de conservação, mas ocorre com certeza, a APA de Maracajaú também, Jenipabu, Bonfim-Guaraíras, RDS é bem forte.

[NUC] Nas audiências eles participaram (órgão públicos), mas não tem muito envolvimento, são presentes nos conselhos gestores e tem uma cadeira nas unidades já criadas, mas assim é bem devagar a questão do turismo.

[NUC]Dentro do Polo, nas reuniões, o IDEMA tem um representante no Polo Costa das Dunas, mas assim, não foi repassado para a gente, se foi discutido, ou se esse representante chamou o NUC para ir apresentar lá, essa proposta de criação. Eu não sei quem é, mas tem cadeira. Porque assim a gente é do próprio órgão, mas tem esse feedback, porque assim o Dunas do Rosado a gente foi lá, e apresentei.

Por meio das falas acima pode-se afirmar que o turismo é uma atividade ocorrente nas UC do Polo Costa das Dunas, e existem dois Parques sendo criados, que por sua categoria permite e incentiva o turismo ecológico. No entanto, os atores do turismo, sejam do setor público e privado não possuem participação no planejamento de atividades turísticas para essas UC.

Os órgãos públicos do turismo comparecem as reuniões, mas a participação efetiva e contribuições para os avanços das discussões do turismo nesses Parques não acontece. O setor privado também não é envolvido nesse cenário, e até mesmo no Polo Costa das Dunas, onde um representante do IDEMA tem assento e representação, não é levantada a questão do PEMAP e PEJ durante as reuniões, diferentemente do que já ocorreu nas reuniões de outros Polos, como a apresentação citada pelo NUC, referente a Dunas do Rosado.

Além disso, observa-se que existe uma falta de comunicação eficiente dentro do próprio IDEMA, pois o NUC é uma das diretorias técnicas do Instituto, mas não tem se quer conhecimento sobre quem seria 0 representante do IDEMA no Polo Costa das Dunas, o que dificulta o levantamento dos debates sobre as UC e a sua relação com a atividade turística.

\section{Discussão sobre a criação de novas UC no Polo Costa das Dunas/RN}

Para resultados da pesquisa solicitou-se atas referente às reuniões do Polo Costa das Dunas no sentido de buscar analisar quais as discussões ocorrentes nesta instância quanto à criação de UC inseridas dentro de municípios que pertencem ao Polo. 
É relevante destacar que foram solicitadas e analisadas um total de 38 atas, pois considerou-se o período onde o processo de criação destas UC deu o seu primeiro passo, a aprovação na Reunião do CONEMA em 2006, sendo assim, fizeram parte desta análise as atas do período de 2006 até 2017. Buscando melhor apresentação dos resultados, optou-se por agrupar as discussões em períodos distintos baseados no Mapa do Turismo Brasileiro e suas atualizações.

Observaram-se nas atas os seguintes aspectos: ano da reunião; representação que se pronunciou, a UC a qual se referiu e as observações realizadas. Sendo assim, o Quadro 5, apresenta os resultados referentes às reuniões ocorridas nos anos de 2006, 2007 e 2008.

Quadro 5: UC no PCD período do Mapa do Turismo Brasileiro 2006 - 2008.

Frame 5: UC in the PCD period of the Brazilian Tourism Map $2006-2008$.

\begin{tabular}{|c|c|c|c|}
\hline Ano & epresentação & UC referida & Observação realizada \\
\hline$\stackrel{\circ}{\circ}$ & $\begin{array}{l}\text { Secretaria de } \\
\text { Estado de } \\
\text { Turismo RN. }\end{array}$ & $\begin{array}{l}\text { APA Recife de } \\
\text { Corais }\end{array}$ & $\begin{array}{l}\text { Ações do PRODETUR voltadas para recuperação e } \\
\text { proteção da APA no valor de } 660 \text { mil reais, onde o } \\
\text { IDEMA fez licitação. No entanto, nenhuma empresa } \\
\text { venceu, O IDEMA deveria então voltar a fazer a } \\
\text { licitação. }\end{array}$ \\
\hline \multirow[b]{2}{*}{ ㅇ } & IDEMA. & $\begin{array}{l}\text { APA Recife de } \\
\text { Corais }\end{array}$ & $\begin{array}{l}\text { Existência de recursos para estudos de zoneamento e } \\
\text { plano de manejo para área, sendo o valor de } 660 \text { mil } \\
\text { reais dependendo ainda de licitação. }\end{array}$ \\
\hline & $\begin{array}{l}\text { Secretaria de } \\
\text { Estado do } \\
\text { Turismo RN. }\end{array}$ & $\begin{array}{l}\text { APA R } \\
\text { Corais }\end{array}$ & $\begin{array}{l}\text { Explica que houve a licitação para elaboração e } \\
\text { implantação do Plano de Manejo, no entanto, foram } \\
\text { apenas dois concorrentes que não atingiram a } \\
\text { pontuação do edital. }\end{array}$ \\
\hline \multirow{3}{*}{ } & PROD & $\begin{array}{l}\text { APA de Jenipabu } \\
\text { APA Bonfim } \\
\text { Guaraíras }\end{array}$ & $\begin{array}{l}\text { Entre as ações concluídas do PRODETUR II estão: a } \\
\text { elaboração do Plano de Manejo e Gestão das duas } \\
\text { APAs, e ainda a Base Cartográfica de Bonfim } \\
\text { Guaraíras. }\end{array}$ \\
\hline & $\begin{array}{l}\text { Associação } \\
\text { Comunitária de } \\
\text { Genipabu }\end{array}$ & APA de Jenipabu & $\begin{array}{l}\text { Questionamento ao IDEMA quanto à implementação } \\
\text { do Comitê Gestor da APA, contando três meses de } \\
\text { aprovação do regimento interno. Recebe a resposta } \\
\text { do IDEMA de que já pode ser iniciado o processo de } \\
\text { gestão compartilhada. }\end{array}$ \\
\hline & $\begin{array}{l}\text { Sindicatc } \\
\text { Bugueiro }\end{array}$ & APA de Jenipabu & $\begin{array}{l}\text { Reivindicação ao IDEMA quanto à concretização do } \\
\text { plano de manejo da APA e a proteção das Dunas. }\end{array}$ \\
\hline 유 & PRODETUR & $\begin{array}{l}\text { APA de Jenipabu; } \\
\text { APA Bonfim } \\
\text { Guaraíras, } \\
\text { APA Recife de } \\
\text { Corais; e Parque } \\
\text { das Dunas. }\end{array}$ & $\begin{array}{l}\text { É sugerida a exclusão de ações da Matriz do } \\
\text { PRODETUR quanto à ação e proteção das APAs; } \\
\text { ação de Elaboração do Plano de Sustentabilidade } \\
\text { Econômica Financeira do Parque das Dunas, } \\
\text { justificando a exclusão por poderem ser contempladas } \\
\text { por meio de recursos do próprio IDEMA. }\end{array}$ \\
\hline \multirow[b]{2}{*}{ 克 } & $\begin{array}{l}\text { SEMURB - } \\
\text { Parque da } \\
\text { Cidade }\end{array}$ & Parque da Cidade & $\begin{array}{l}\text { Convida-se para conhecerem o Parque da Cidade, UC } \\
\text { municipal, empreendimento turístico, com auditório, } \\
\text { biblioteca, centro de educação ambiental e trilhas. }\end{array}$ \\
\hline & $\begin{array}{l}\text { Associação } \\
\text { Comunitária de } \\
\text { Genipabu }\end{array}$ & APA de Jenipabu & $\begin{array}{l}\text { Chama-se atenção para o descaso com a localidade, } \\
\text { onde pode ser citada como problemas, a falta de posto } \\
\text { policial, de receptivos, animais pelas ruas e lixo a céu } \\
\text { aberto. }\end{array}$ \\
\hline
\end{tabular}

Fonte: autoria própria, 2017.

Source: Autoría propia, 2017. 
Referente ao Quadro 5 é possível notar que as principais discussões perpassam sobre as APAs de Jenipabu e Recife dos Corais, apesar de também terem sido citadas a APA de Bonfim-Guaíra, Parque das Dunas e o Parque da Cidade. Nota-se que as ações do PRODETUR aglutinam, em certo modo, a questão das UC da Região, principalmente ao que se compete em investimentos e instrumentos para melhor gestão da área.

As representações que são formadas por membros das comunidades locais, como Associação Comunitária de Genipabu e o Sindicato de Bugueiros do $\mathrm{RN}$, abordam questões de maior ligação com os impactos gerados e percebidos, tanto nos recursos naturais quanto em aspectos de necessidade de efetivação e melhoria na gestão da APAJ.

Quanto às UC em criação, não houve observações no período que compreende os anos de 2006, 2007 e 2008. Mesmo com assento no Conselho, o IDEMA, órgão responsável pela criação e gestão das UC no $\mathrm{RN}$, não levantou as discussões sobre a temática.

Em 2009 é lançada uma nova configuração do Mapa do Turismo Brasileiro, o Polo Costa das Dunas nesse período, abarcava 21 municípios. O quadro 6, refere-se às discussões que foram feitas sobre UC nos anos de 2009, 2010, 2011 e 2012.

Quadro 6: UC no PCD período do Mapa do Turismo Brasileiro 2009 - 2012.

Frame 6: UC in the PCD period of the Brazilian Tourism Map 2009 - 20012.

\section{Ano Representação UC referida Observação realizada}

START Pesquisa UC em criação Ao apresentar os componentes do PDTIS, cita-se como e Consultoria $\quad$ estratégia: a) elaborar estudos para criação de UC para Técnica os complexos de lagoas e dunas; b) criação de planos de manejo para UC a serem criadas; c) criação de plano de manejo para UC em processo de criação: UC Morro do Careca, Parque Estadual Mangues do Potengi, e Parque Estadual do Jiqui.

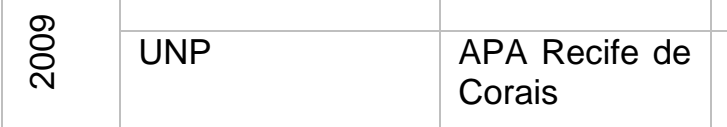

Questiona sobre a delimitação de áreas de preservação e de uso que na apresentação da START sobre o PDTIS não foi comentada a delimitação referente a Rio do Fogo e Maracajaú.

\begin{tabular}{|c|c|c|c|}
\hline & $\begin{array}{l}\text { START Pesquisa } \\
\text { e Consultoria } \\
\text { Técnica. }\end{array}$ & $\begin{array}{ll}\text { Áreas de } & \\
\text { Proteção } & \\
\text { Ambiental } & \end{array}$ & $\begin{array}{l}\text { Ao responder a solicitação do Secretário do Polo, em } \\
\text { inserir um item no PDITS sobre criação dos planos de } \\
\text { manejo de APAs, o representante da START informa } \\
\text { que já existia um item sobre isso. }\end{array}$ \\
\hline 웅 & IDEMA & $\begin{array}{ll}\text { APA } & \text { de } \\
\text { Jenipabu }\end{array}$ & $\begin{array}{l}\text { E comentado que foram tomadas algumas ações } \\
\text { práticas na APA referente a sinalização e } \\
\text { monitoramento do fluxo de movimentação de veículos } \\
\text { do Cordão Dunar da APAJ. }\end{array}$ \\
\hline \multirow{2}{*}{ হ } & $\begin{array}{l}\text { Procuradoria } \\
\text { Geral } \\
\text { Estado/RN }\end{array}$ & $\begin{array}{l}\text { Parque } \\
\text { Nacional } \\
\text { Furna Feia. }\end{array}$ & $\begin{array}{l}\text { Apresenta-se a proposta de criação do Parque Nacional } \\
\text { Furna Feia, sendo o primeiro Parque Nacional do RN. } \\
\text { Informa-se que o processo encontra-se nos tramites } \\
\text { finais para criação, e na reunião do Polo é solicitado o } \\
\text { apoio formal dos conselheiros a essa criação. }\end{array}$ \\
\hline & $\begin{array}{l}\text { ONG Oceânica - } \\
\text { Pesquisa, } \\
\text { Educação } \\
\text { Conservação. }\end{array}$ & $\begin{array}{l}\text { Parque } \\
\text { Nacional } \\
\text { Furna Feia. }\end{array}$ & $\begin{array}{l}\text { Questiona como foram levantadas as informações e } \\
\text { estudos sobre a criação do Parque. A procuradoria, diz } \\
\text { que será disponibilizada a apresentação mais } \\
\text { detalhada. }\end{array}$ \\
\hline
\end{tabular}

Continua... 
...continuação.

\begin{tabular}{|c|c|c|c|}
\hline \multirow[t]{2}{*}{ Ano } & Representação & UC referida & Observação realizada \\
\hline & $\begin{array}{l}\text { ONG } \\
\text { RESPOSTA }\end{array}$ & $\begin{array}{l}\text { Parque } \\
\text { Nacional } \\
\text { Furna Feia. }\end{array}$ & $\begin{array}{l}\text { Questiona para que serviria o apoio formal dos } \\
\text { conselheiros, sendo respondido pela procuradoria que } \\
\text { tal apoio facilitaria o tramite junto à Casa Civil da } \\
\text { Presidência, compondo um indicativo de não resistência } \\
\text { por parte dos segmentos locais. }\end{array}$ \\
\hline \multirow[t]{2}{*}{$\bar{N}_{\mathcal{N}}$} & $\begin{array}{l}\text { Representante do } \\
\text { Parque Estadual } \\
\text { das Dunas }\end{array}$ & $\begin{array}{l}\text { Parque } \\
\text { Dunas }\end{array}$ & $\begin{array}{l}\text { É interrogado sobre o Parque das Dunas não se } \\
\text { encontrar entre os Parques da Copa. A resposta da } \\
\text { Procuradoria do Estado é que não existe definição de } \\
\text { Parques Estaduais ou Municipais para integrar o Projeto } \\
\text { de Parques da Copa, além disso, ressalta que o Parque } \\
\text { das Dunas não possui capacidade suficiente para } \\
\text { atender os turistas desse contexto. }\end{array}$ \\
\hline & $\begin{array}{l}\text { Procuradoria } \\
\text { Geral do } \\
\text { Estado/RN. }\end{array}$ & $\begin{array}{l}\text { APA Recife } \\
\text { dos Corais }\end{array}$ & $\begin{array}{l}\text { Sobre o PDTIS é ressaltada a necessidade de incluir } \\
\text { nas ações a APA tendo em vista a sua contribuição para } \\
\text { o turismo sustentável. Em resposta, a START explica } \\
\text { que a APA já faz parte das } 5 \text { UC definidas no PDTIS. }\end{array}$ \\
\hline \multirow{2}{*}{$\bar{\Sigma}$} & UFRN & $\begin{array}{l}\text { Parque Furna } \\
\text { Feia, Mata da } \\
\text { Pipa, Parque } \\
\text { das Dunas e } \\
\text { Parque da } \\
\text { Cidade. }\end{array}$ & $\begin{array}{l}\text { Ao apresentar o Projeto de Geoturismo é ressaltada a } \\
\text { existência de recursos de investimento para o RN em } \\
\text { dois Parques Federal, no âmbito do projeto Copa } \\
\text { Sustentável, e o participante sugere o Parque Furna } \\
\text { Feia e a Mata da Pipa, além da inserção do Parque das } \\
\text { Dunas e o Parque da Cidade para serem trabalhados } \\
\text { sob a ótica biológica e geológica. }\end{array}$ \\
\hline & $\begin{array}{l}\text { Procuradoria } \\
\text { Geral do } \\
\text { Estado/RN. }\end{array}$ & $\begin{array}{l}\text { Parque do } \\
\text { Jiqui e Parque } \\
\text { Mangues do } \\
\text { Potengi }\end{array}$ & $\begin{array}{l}\text { Trata-se de estruturação de novos atrativos no Polo, é } \\
\text { citado a possível criação de um Jardim Botânico Natural } \\
\text { dentro do Parque do Jiqui, além de trilhas naturais. } \\
\text { Quanto ao Parque do Mangues, é cita-se a instalação } \\
\text { do museu do mangue, bem como passeios pelos } \\
\text { manguezais. }\end{array}$ \\
\hline$\frac{N}{\sim}$ & $\begin{array}{l}\text { Procuradoria } \\
\text { Geral do } \\
\text { Estado/RN. }\end{array}$ & $\begin{array}{lr}\text { Parque das } \\
\text { Dunas } \quad \text { e } \\
\text { Parque } \\
\text { Nacional } \\
\text { Furna Feia }\end{array}$ & $\begin{array}{l}\text { Informa-se que a sinalização do Parque das Dunas } \\
\text { estava sendo renovada para incluir língua inglesa e } \\
\text { espanhola. Além disso, ressalta que dia } 05 \text { de Junho foi } \\
\text { criado o primeiro Parque Nacional do Estado, o Furna } \\
\text { Feia. }\end{array}$ \\
\hline స̃ & $\mathrm{ABIH}$ & $\begin{array}{l}\text { APA de } \\
\text { Jenipabu }\end{array}$ & $\begin{array}{l}\text { O representante solicita espaço para o IDEMA } \\
\text { apresentar a situação de degradação da APA, com } \\
\text { elevado número de construções de casa dentro da área. }\end{array}$ \\
\hline
\end{tabular}

Fonte: autoria própria, 2017.

Source: Autoría propia, 2017.

Como pode ser visto no quadro 6, o período apresentado, traz consigo algumas questões cabíveis de discussão. Inicialmente é pertinente destacar a elaboração do PDTIS em se tratando das discussões sobre UC desse período, chama-se atenção para a relevância de inserção dessas áreas naturais já criadas no planejamento e elaboração do PDTIS, alegando principalmente, o poder de atratividade turística e contribuição dessas áreas para o desenvolvimento do turismo sustentável.

Sobre UC legalmente já instituídas, contatou-se algumas considerações sobre possíveis melhorias e investimentos nessas áreas, como na APAJ onde foram realizadas algumas ações de sinalização e monitoramento, quanto ao Parque das Dunas informaram que está sendo implantada uma nova sinalização nos idiomas inglês e espanhol, e na APARC a conclusão do Plano de Manejo da área. 
No cenário das UC em criação podem-se observar algumas discussões nesse período, percebe-se que a procuradoria do Estado, em 2011, leva para apresentação no Polo a proposta de criação do primeiro Parque Nacional no RN, o Furna Feia, na perspectiva de conseguir apoio formal dos membros, pois considera-se que esse fato pode colaborar no aceleramento do processo ao demonstrar apoio dos segmentos locais, em 2012 o Parque recebe o decreto de criação.

Quanto às UC Estaduais em criação no Polo Costa das Dunas, observa-se por meio do quadro 6 as primeiras discussões dentro da instância de governança, primeiramente em 2009, a empresa de consultoria START relata que dentro do PDTIS a criação das UC (UC Morro do Careca, Parque Mangues do Potengi e Parque do Jiqui) está atrelada ao produto de melhoria na qualidade ambiental e melhor aproveitamento dos recursos naturais de maneira sustentável.

Ainda sobre UC em criação do Polo, a Procuradoria do Estado comenta que essas áreas podem constituir novos atrativos turísticos na região, dando enfoque para os dois Parques que são objetos de estudo da presente pesquisa, o Parque Estadual do Jiqui, onde de acordo com a representante dele existe a possibilidade de criação de um jardim botânico natural, além de trilhas naturais. E sobre o Parque Estadual Mangues do Potengi é cogitada a instalação do museu do mangue, bem como, passeios pelos manguezais, o que consiste em ser um diferencial em virtude de poucas propostas nesse sentido no Brasil.

A partir do ano de 2013, percebe-se no quadro 7 que as discussões sobre UC dentro do Polo Costa das Dunas foram escassas e referente às UC em criação não foi encontrada nenhuma observação nesse período.

Quadro 7: UC no PCD período do Mapa do Turismo Brasileiro 2013 - 2015.

Frame 7: UC in the PCD period of the Brazilian Tourism Map $2013-2015$.

\begin{tabular}{|c|c|c|c|}
\hline Reunião & Representação & UC referida & $\overline{\text { Observação realizada }}$ \\
\hline$\frac{m}{\grave{N}}$ & $\begin{array}{l}\text { Procuradoria } \\
\text { Geral do } \\
\text { Estado/RN. }\end{array}$ & $\begin{array}{l}\text { Unidades de } \\
\text { Conservação } \\
\text { do RN }\end{array}$ & $\begin{array}{l}\text { Ao falar da Campanha Passaporte Verde para a } \\
\text { Copa do Mundo, é citado que o RN não terá conflitos } \\
\text { na perspectiva de valorização das UCs, pois muitos } \\
\text { pontos turísticos estão inseridos dentro dessas } \\
\text { áreas. }\end{array}$ \\
\hline$\stackrel{n}{0}$ & OAB & $\begin{array}{l}\text { Parques } \\
\text { Estaduais }\end{array}$ & $\begin{array}{l}\text { Ao apresentar aspectos relacionados à Lei Geral do } \\
\text { Turismo do RN, fala-se sobre a criação do Fundo do } \\
\text { Desenvolvimento do Turismo - FUNDETUR de } \\
\text { natureza financeira e com objetivo de financiar } \\
\text { projetos voltados para o turismo. Entre as fontes } \\
\text { constituintes desse recurso estão Receitas dos } \\
\text { Parques Estaduais. }\end{array}$ \\
\hline
\end{tabular}

Fonte: autoria própria, 2017.

Source: Autoría propia, 2017.

De acordo com o quadro acima que no intervalo de 3 anos, apenas duas observações foram feitas sobre UC durante as reuniões do Polo. Nesta perspectiva, tratando-se das observações sobre UC do Polo ocorridas entre os anos de 2006 até 2017 é possível analisar que essas não acontecem de 
maneira expressiva, são levantamentos incipientes e por vezes não são debatidos de maneira contínua nas demais reuniões.

Nota-se que apesar do IDEMA ter assento e comparecer nas reuniões, não é um órgão principal que levanta as questões de UC da Região, sendo então a Procuradoria do Estado a instituição que mais colabora nas discussões sobre UC do Polo.

Sobre o Parque do Mangues do Potengi e Parque do Jiqui, as observações são ainda mais limitadas, identificando apenas duas considerações sobre essas UC, a primeira em 2009, dentro da abordagem do PDTIS, em que a empresa de consultoria responsável pelo Plano apresenta as UC em criação como estratégias para melhoria da qualidade ambiental do Polo e uso sustentável dessas áreas. A segunda consideração ocorreu em 2011, em que a Procuradoria do Estado entende que os dois Parques consistem em alternativas para estruturação de novos atrativos turísticos na Região do Polo.

\section{Considerações finais}

A busca por compreender a abordagem do turismo no processo de criação de novas UC que tem em suas propostas o incentivo a atividade turística, possibilita o entendimento de como essa atividade está sendo planejada e quem são os atores que estão discutindo a temática dentro no cenário de áreas naturais protegidas.

Afirma-se com base nos resultados do presente artigo, que os Parques Mangues do Potengi e Jiqui possuem um apelo tímido voltado para a prática do turismo, mas que em algumas discussões são vistos como atrativos em potencial, inclusive para diferenciação da oferta existentes na Região Turística Costa das Dunas.

No cenário de reuniões referentes a criação dos parques, bem como as discussões do Polo Costa das Dunas, a participação de atores do turismo, de comunidades locais, setores privados e comunidade civil como um todo é escassa. Mesmo com elevada contribuição das UC na oferta turística da região, os debates levantados na instância de governança tratase de discussões incipientes e quase inexistentes, o que posteriormente pode resultar em diferentes conflitos principalmente de ordem socioeconômica.

A criação dos PEMAP e PEJ é percebida como incremento e diversificação da oferta turística do polo, a escolha da categoria Parque induz a presença de turistas e visitantes como forma de contribuição para o desenvolvimento socioeconômico da área, no entanto, no polo, que tem como responsabilidade debater sobre planejamento e gestão do turismo da região, as citações referentes as áreas criadas e em criação são carentes.

Sendo assim, afirma-se que o diálogo entre partes interessadas no turismo em áreas naturais protegidas no Polo Costa das Dunas é frágil, uma vez que, na perspectiva do planejamento que antecede a instituição das UC 
não se discute com profundidade e continuidade as ações, contribuições e estratégias para avanço dos processos.

Dessa forma, apresenta-se alguns elementos que devem ser considerados e mais bem discutidos durante esse processo de criação de UC como: o maior envolvimento e participação por parte tanto de comunidades locais, como atores públicos e privados do turismo em reuniões e audiências sobre a criação da UC, além de buscar delimitar de maneira mais clara as propostas vinculadas ao turismo e visitação dos Parques.

Como indicação de trabalho futuros sugere-se análises com demais UC em criação que possuem algum apelo voltado para o turismo, buscando compreender como essa atividade está sendo planejada dentro desse contexto. O presente trabalho limita-se em análise de processos com base em documentos e uma entrevista com o Núcleo de Unidades de Conservação do IDEMA, o que poderia ser abrangente para demais órgãos e representantes envolvidos com a criação de UC.

\section{Referências}

BRASIL, Ministério do Turismo. Módulo Operacional 3: Institucionalização da instância de governança regional. Brasília: Ministério do Turismo, 2007.

BRASIL. Ministério do Meio Ambiente. (2008). Criação de UC. Disponivel em $\quad<$ http://www.mma.gov.br/areas-protegidas/unidades-deconservacao/criacao-ucs>. Acesso em:10 de Setembro de 2016.

BRASIL. Ministério do Meio ambiente. O SNUC. São Paulo,2011.

CNUC/MMA. Painel de Unidades de Conservação Brasileiras. Disponível em:

$<$ https://app.powerbi.com/view?r=eyJrljoiMjUxMTU0NWMtODkyNC00NzNiL WJiNTQtNGI3NTI2NjliZDkzliwidCI6ljM5NTdhMzY3LTZkMzgtNGMxZi1hNGJ hLTMzZThmM2M1NTBINyJ9>. Acesso em 27 de fevereiro de 2021.

DECRETO n 4.340, de 22 de Agosto de 2002. (2002). Brasília, DF. Disponível em $<$ http://www.planalto.gov.br/ccivil 03/decreto/2002/d4340.htm >. Acesso em 29 de Novembro de 2018.

DRUMMOND, J. A.; FRANCO, J. L.; OLIVEIRA., D. D. Uma análise sobre a história e a situação das unidades de conservação no Brasil. Conservação da Biodiversidade, legislação e políticas públicas, 341-385, 2010.

EAGLES, P. F.; MCCOOL, S. F.; HAYNES, C. D. Sustainable Tourism in Protected Areas: Guidelines for Planning and Management. Suíça e Cambridge: IUCN Gland,2002.

FARAJI, A.; AGHAJANI, S. The Relationship between Tourism and Environment. Iranian Journal of Tourism \& Hospitality, p. 37-48. 2010. 
FUNDAÇÃO PARA O DESENVOLVIMENTO SUTENTÁVEL DA TERRA POTIGUAR DO RIO GRANDE DO NORTE \& INSTITUTO DE DEFESA DO MEIO AMBIENTE DO RIO GRANDE DO NORTE . Parque Estadual dos Mangues plano de ação emergencial. Natal: FUNDEP/IDEMA,2009.

FUNDAÇÃO PARA O DESENVOLVIMENTO SUTENTÁVEL DA TERRA POTIGUAR DO RIO GRANDE DO NORTE \& INSTITUTO DE DEFESA DO MEIO AMBIENTE DO RIO GRANDE DO NORTE. Parque Estadual do Jiqui plano de ação emergencial. Natal: FUNDEP/IDEMA,2009.

GIL, A. C. Métodos e técnicas de pesquisa social. São Paulo: Atlas,2008.

HERNÁNDEZ, J. R.; LÓPEZ, O. I. (2018). Conservación y desarrollo, el caso del ecoturismo: una política ambiental fallida en la Reserva de la Biosfera La Encrucijada, Chiapas. EI Periplo Sustentable,p. 82 - 108,2018

IBGE. Instituto de Geografia e Estatística. Censo Demográfico 2010. Disponível em $<$ http://www.ibge.gov.br/home/estatistica/populacao/censo2010/caracteristica s da populacao/caracteristicas da populacao tab municipios zip xls.shtm >. Acesso em: 10 de Fevereiro. 2017.

ICMBIO. Criação de unidades de conservação. Disponível em: $<$ http://www.icmbio.gov.br/portal/criacaodeunidadesdeconservacao $>$. Acesso em 22 de abril, 2017.

ICMBIO. Instrução Normativa ICMBIO n 5, de 15 de Maio de 2008, 2008.

ICMBIO. Monitoramento da visitação em Unidades de Conservação Federais: resultados de 2019 e breve panorama histórico. Brasília: Ministério do Meio Ambiente, 2020.

IDEMA (2014). Unidades Estaduais de Conservação Ambiental do RN. Disponível em: $<$ http://www.idema.rn.gov.br/Conteudo.asp?TRAN=ITEM\&TARG=334\&ACT = \&PAGE $=0 \& \mathrm{PARM}=\& \mathrm{LBL}=$ Unidades+de+Conserva\%E7\%E30>. Acesso em 10 de Agosto de 2016.

JIMÉNEZ, M. B.; SALGUERO, B. M.; VÁZQUES, M. L.; BORREGO, S. Á.; SALAZAR, J. L.; PADILLA, E. V.; RUBIO, A. O. Percepción de los prestadores de servicios dentro de Áreas Naturales Protegidas sobre la eficacia de las políticas ambientales ahí implementadas y su impacto sobre el bienestar de la comunidad. Caso: Cabo Pulmo, B. C. S. México. EI Periplo Sustentable, 760 - 797,2017.

LEI no 9.985, 18 jul. 2000. SNUC - SNUC. Brasília, DF. Disponível em $<$ http://www.planalto.gov.br/ccivil 03/leis//9985.htm>. Acesso em 10 de Setembro de 2016,2000.

LEITE, M. S.; GEISELER, S.; PINTO, R. S. Como criar unidades de conservação: guia prático para Pernambuco. Recife: CEPAN, 2011.

LIMA, M. (Eco) turismo em Unidades de Conservação. In: RODRIGUES, A. Ecoturismo no Brasil: possibilidades e limites. São Paulo: Contexto, 2003. 
OLIVEIRA, F. T.; BRANDÃO, R. A. Perspectivas do ecoturismo: uma análise sobre características e percepções locais na Floresta Nacional SaracáTaquera, Pará - Brasil. El Periplo Sustentable, p. 77 - 105, 2016.

OLIVEIRA, W. A. Turismo, unidades de conservação e inclusão social: Uma análise da Área de Proteção Ambiental Recifes de Corais (APARC) e Área de Proteção Ambiental Jenipabu (APAJ), RN. Dissertação de mestrado. Universidade Federal do Rio Grande do Norte, Natal, RN, Brasi,2017.

PIRES, P. As Múltiplas Facetas e Implicações da Relação Turismo e Meio Ambiente. Anais do IV SeminTUR - Seminário de Pesquisa em Turismo do MERCOSUL, 1-17, 2006.

PIRES, P.S.; RUGINE, V.M.T. Reconhecimento do Uso Público nos Parques Estaduais no Brasil com ênfase na visitação turística. Revista Brasileira de Ecoturismo, São Paulo, v. 11, n. 14, p. 61-80, abr. 2018.

QUEIROZ, E.D.; VALLEJO, L.R. USO PÚBLICO EM UNIDADES DE CONSERVAÇÃO: entre o ideal e o real. Revista Eletrônica Uso Público em Unidades de Conservação, Niterói, v. 5, n. 9, p. 1-15, dez. 2017.

RODRIGUES, S.L.; Souza, M. A organização de redes de governança na regionalização do turismo: microrregião uva e vinho - Rio Grande do Sul Brasil. Geosaberes, 278 - 288, 2016.

SETUR/RN. Plano de desenvolvimento integrado do turismo sustentável - PDTIS. Natal, 2011.

SOARES, A.S. O ecoturismo sob a égide da sociedade do consumo: um estudo das Unidades de Conservação de uso sustentável do RN. Dissertação de mestrado (Mestrado em turismo) - Natal, RN: UFRN,2011.

SONAGLIO, K. E. A transdisciplinaridade no processo de planejamento e gestão do ecoturismo em Unidades de Conservação. Tese de Doutorado (Doutorado em Engenharia Ambiental) - Programa de Pós-graduação em Engenharia Ambiental, UFSC, Florianópolis, 2006.

SONAGLIO, K. E.; LAPOLLI, É. M. Uma Abordagem Transdisciplinar para o Desenvolvimento Sustentável do Ecoturismo. Turismo - Visão e Ação, p. 161-168, 2003.

SUAREZ, C. F. Turismo sustentável, qualidade de vida e políticas públicas, em unidades de conservação: um estudo de caso em Vargem São Paulo (APA do Sistema Cantareira). Campinas: Universidade Estadual de Campinas,2010.

VALLEJO, L. R. Uso público em áreas protegidas: atores, impactos, diretrizes de planejamento e gestão. Universidade Federal Fluminense, 13$26,2013$.

VEAL, A. Metodologia de pesquisa em lazer e turismo. São Paulo: Aleph, 2011. 
Fernanda Raphaela Alves Dantas: Universidade Federal do Rio Grande do Norte, Natal, RN, Brasil.

E-mail: nandaraphaela@hotmail.com

Link para o currículo Lattes: http://lattes.cnpq.br/5037254795248546

Kerlei Eniele Sonaglio: Universidade de Brasília, Brasília, DF, Brasil.

E-mail: kerleisonaglio@gmail.com

Link para o currículo Lattes: http://lattes.cnpq.br/1823313556538300

Data de submissão: 08 de julho de 2020

Data de recebimento de correções: 10 de dezembro de 2020

Data do aceite: 10 de dezembro de 2020

Avaliado anonimamente 